\title{
Review \\ Unravelling Formaldehyde Metabolism in Bacteria: Road towards Synthetic Methylotrophy
}

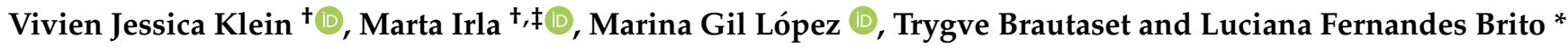

Citation: Klein, V.J.; Irla, M.; Gil López, M.; Brautaset, T.; Fernandes Brito, L. Unravelling Formaldehyde Metabolism in Bacteria: Road towards Synthetic Methylotrophy. Microorganisms 2022, 10, 220. https://doi.org/10.3390/ microorganisms 10020220

Academic Editor: Hiroya Yurimoto

Received: 16 December 2021

Accepted: 17 January 2022

Published: 20 January 2022

Publisher's Note: MDPI stays neutral with regard to jurisdictional claims in published maps and institutional affiliations.

Copyright: (C) 2022 by the authors. Licensee MDPI, Basel, Switzerland. This article is an open access article distributed under the terms and conditions of the Creative Commons Attribution (CC BY) license (https:// creativecommons.org/licenses/by/ $4.0 /)$.

\author{
Department of Biotechnology and Food Science, Norwegian University of Science and Technology, \\ 7491 Trondheim, Norway; vivien.j.klein@ntnu.no (V.J.K.); marta.k.irla@ntnu.no (M.I.); \\ marina.g.lopez@ntnu.no (M.G.L.); trygve.brautaset@ntnu.no (T.B.) \\ * Correspondence: luciana.f.d.brito@ntnu.no; Tel.: +47-4136-6322 \\ + These authors contributed equally to this work. \\ $\ddagger$ Current Address: Department of Biological and Chemical Engineering, Aarhus University, \\ 8000 Aarhus, Denmark.
}

\begin{abstract}
Formaldehyde metabolism is prevalent in all organisms, where the accumulation of formaldehyde can be prevented through the activity of dissimilation pathways. Furthermore, formaldehyde assimilatory pathways play a fundamental role in many methylotrophs, which are microorganisms able to build biomass and obtain energy from single- and multicarbon compounds with no carbon-carbon bonds. Here, we describe how formaldehyde is formed in the environment, the mechanisms of its toxicity to the cells, and the cell's strategies to circumvent it. While their importance is unquestionable for cell survival in formaldehyde rich environments, we present examples of how the modification of native formaldehyde dissimilation pathways in nonmethylotrophic bacteria can be applied to redirect carbon flux toward heterologous, synthetic formaldehyde assimilation pathways introduced into their metabolism. Attempts to engineer methylotrophy into nonmethylotrophic hosts have gained interest in the past decade, with only limited successes leading to the creation of autonomous synthetic methylotrophy. Here, we discuss how native formaldehyde assimilation pathways can additionally be employed as a premise to achieving synthetic methylotrophy. Lastly, we discuss how emerging knowledge on regulation of formaldehyde metabolism can contribute to creating synthetic regulatory circuits applied in metabolic engineering strategies.
\end{abstract}

Keywords: formaldehyde; assimilation; dissimilation; methylotrophy; synthetic methylotrophy; regulation systems

\section{Introduction}

Formaldehyde is toxic to all living organisms due to its nonspecific reactions with proteins and nucleic acids, giving rise to the widespread development of mechanisms for its detoxification. However, the focus of this review is formaldehyde metabolism in microorganisms, specifically in bacteria [1]. The primary atmospheric sources of formaldehyde are either anthropogenic (indoor pollution through building materials, vehicle exhaust gases, various combustion sources, and fugitive industrial emissions) or biogenic (live and decaying plants, biomass burning, and seawater) [2-4]. Formaldehyde can also be formed as part of bacterial metabolism in biological processes such as the demethylation of lignins or Strecker degradation of glycine with methylglyoxal [5]. High levels of formaldehyde can hamper cell functions due to its cytotoxic effect, which is provoked by its electrophilic reactivity [6]. Formaldehyde forms reactive dihydroxydimethyl peroxides and free radicals in the presence of oxidizing molecules, causing oxidative stress and ultimately cell death [7-10]. Unspecific binding of formaldehyde to various macromolecules leads to the inactivation of their biological functions [11]. This way, exposure to formaldehyde can damage vital cell components as DNA, RNA, and proteins through processes such as a multistep formation of adducts and cross-links [6,12-15]. 
Despite its highly toxic properties, formaldehyde acts as a key intermediate in methylotrophic metabolism directly originating from the oxidation of one-carbon (C1) compounds, excluding rare exceptions $[1,6,16-20]$. Methylotrophs are microorganisms with the ability to build biomass and obtain energy from either single-carbon compounds such as methane, methanol, or formate, or multicarbon compounds with no carbon-carbon bonds such as dimethyl ether and dimethylamine [20]. All those compounds are commonly known as $\mathrm{C} 1$ compounds and will hereafter be referred to as such. Methylotrophs have specifically developed formaldehyde assimilation (i.e., fixation) systems in the course of evolution in order to use formaldehyde for biomass production [1]. Four different cyclic $\mathrm{C} 1$ assimilatory pathways have been described for aerobic methylotrophs: formaldehyde fixation can take place via the ribulose monophosphate (RuMP) cycle and the serine cycle in bacteria, while yeasts use the xylulose monophosphate (XuMP) pathway; in a few known methylotrophs, after oxidation of $\mathrm{C} 1$ substrates to $\mathrm{CO}_{2}$, assimilation of the latter takes place via the ribulose bisphosphate (RuBP) pathway as in classic autotrophic microorganisms [20-22]. Because the focus of this review is formaldehyde assimilation in bacteria, the XuMP pathway will not be further explored [23]. Likewise, as anaerobic methylotrophy does not involve formaldehyde and the RuBP pathway relies on autotrophic $\mathrm{CO}_{2}$ assimilation, they will also be excluded from this review [23]. Alongside these assimilation pathways, methylotrophs have also developed formaldehyde dissimilation (i.e., oxidation) mechanisms similar to all living organisms in order to cope with excess formaldehyde and preserve their cellular functions [1]. Remarkably, in methylotrophic Methylorubrum extorquens (formerly Methylobacterium extorquens) AM1, tolerance to formaldehyde is heterogeneously distributed in bacterial cell populations with two distinct gene expression profiles characteristic for tolerant or susceptible cells. While susceptible cells exhibit global stress response to treatment with formaldehyde, the response of the tolerant subpopulation does not seem to involve the formaldehyde oxidation pathway but features a number of chaperones and electron transport chain factors [24].

Formaldehyde dissimilation pathways are present not only in methylotrophs but also in nonmethylotrophic microorganisms to prevent the toxic impact of environmental formaldehyde [1]. While for most bacteria, except for methylotrophs, the well-known strategy to maintain intracellular concentrations of formaldehyde at subtoxic levels is its dissimilation, there have recently been attempts at engineering synthetic formaldehyde assimilation pathways into their metabolism using mainly Escherichia coli and Corynebacterium glutamicum but also Pseudomonas putida and most recently Bacillus subtilis as host strains $[25,26]$. Synthetic methylotrophy is based on implementing methylotrophic pathways into nonmethylotrophic platform microorganisms following synthetic biology approaches with only one successful attempt at autonomous methylotrophy so far without the use of cosubstrate, at growth rates of $0.09 \mathrm{~h}^{-1}$ [27]. Although employing natural methylotrophs as bioproduction platforms seems to be a more straightforward approach than creating synthetic methylotrophs, it exhibits limitations due to a narrow understanding of their metabolism and physiology and a restricted synthetic biology toolbox [28]. As an alternative strategy, the transfer of methylotrophy into well-established and biotechnologically relevant hosts offers the possibility of a streamlined implementation of C1-based bioproduction processes.

In the past decades, several review papers have described different aspects of formaldehyde metabolism in bacteria and, among others, the following issues were covered: (i) Stress responses of bacterial pathogens to formaldehyde in the environment [19]; (ii) Different cofactor-dependent formaldehyde oxidation pathways in methylotrophic bacteria [29]; (iii) Native methanol metabolism as a foundation for the design of synthetic methylotrophy [30]; (iv) Challenges and opportunities regarding the engineering of unnatural methylotrophic cell factories for methanol- and formate-based biomanufacturing [31-36].

A comprehensive understanding of formaldehyde metabolism and its regulation is indispensable for designing synthetic methylotrophic pathways, which will be further explored in this review. To this end, in addition to the formaldehyde assimilation and 
dissimilation in native methylotrophs, we will provide examples of formaldehyde dissimilation systems in nonmethylotrophic bacteria given that native methylotrophic routes share multiple enzymes with formaldehyde dissimilatory pathways in nonmethylotrophs. This will be done focusing mainly on chosen organisms used either as gene donors or hosts in attempts at establishing synthetic methylotrophy. For the latter, E. coli and C. glutamicum will serve as leading examples to showcase the prior attempts to introduce formaldehyde assimilation pathways into nonmethylotrophic bacteria due to their relevance as model organisms and their industrial applications [37,38]. Altogether, we present an exhaustive description of pathways involved in formaldehyde metabolism, both in methylotrophs and nonmethylotrophs, together with examples of how this crucial knowledge has been applied in the establishment of synthetic methylotrophy thus far (Figure 1).

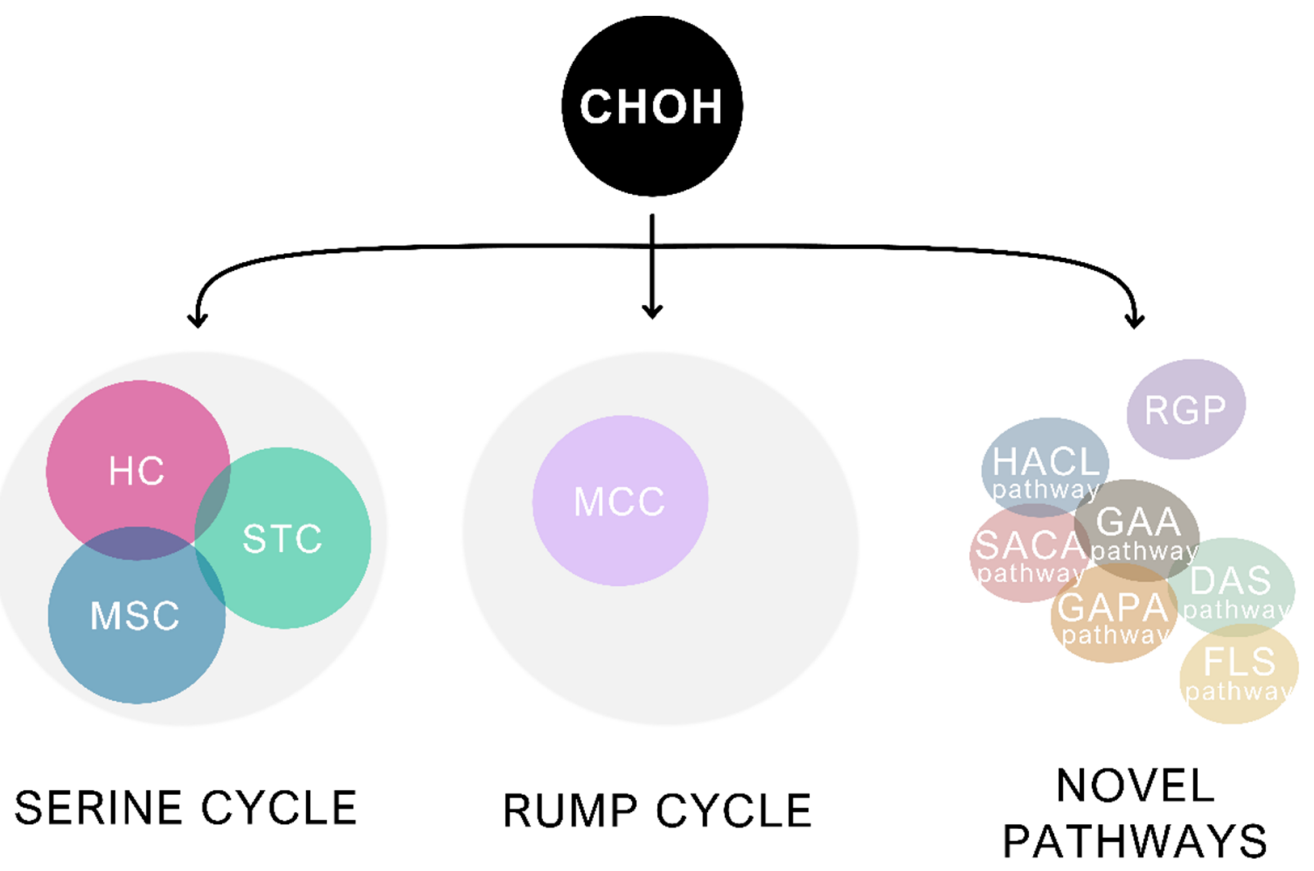

Figure 1. Schematic overview of the native, modified, and novel methylotrophic pathways in bacteria described in this review. $\mathrm{CHOH}=$ formaldehyde; $\mathrm{HC}=$ homoserine cycle; $\mathrm{STC}=$ serine-threonine cycle; $\mathrm{MSC}=$ modified serine cycle; $\mathrm{MCC}=$ methanol condensation cycle; $\mathrm{RGP}=$ reductive glycine pathway; HACL = 2-hydroxyacyl-CoA-lyase; SACA = synthetic acetyl-CoA; GAA = glycolaldehyde assimilation; GAPA = glycolaldehyde-allose 6-phosphate; DAS = dihydroxyacetone synthase; FLS $=$ formolase .

\section{Understanding and Modification of Formaldehyde Dissimilation Pathways for the Optimization of Synthetic Methylotrophy}

Due to the toxic properties of formaldehyde described in the previous Section, its dissimilation is an indispensable feature of bacterial metabolism. Formaldehyde dissimilation in methylotrophic and nonmethylotrophic bacteria relies on either its reaction with sugar phosphates or its oxidation to formate and further to $\mathrm{CO}_{2}$, which yields reduction equivalents but does not generate biomass precursors [20]. In this Section, we provide insight into formaldehyde dissimilation pathways and their importance in native methylotrophy (Section 2.1) and show how modification of such dissimilatory pathways in nonmethylotrophic bacteria aids in synthetic methylotrophy efforts (Section 2.2).

\subsection{Formaldehyde Dissimilatory Pathways in Native Methylotrophs}

In natural methylotrophs, utilization of $\mathrm{C} 1$ compounds starts with their oxidation to the key intermediate formaldehyde prior to either formaldehyde assimilation into central carbon metabolism or its dissimilation [20-22]. While formaldehyde dissimilation occurs in both methylotrophic and nonmethylotrophic bacteria by means of cyclic or linear pathways 
(Tables 1 and 2, Figure 2), they have two primary functions in methylotrophic bacteria: the control of formaldehyde concentrations below the toxicity threshold and contribution to energy metabolism [20]. The $\mathrm{NAD}(\mathrm{P})^{+}$-dependent formaldehyde dehydrogenases (Faldh) require additional cofactors for their activity, such as pterins-tetrahydrofolate $\left(\mathrm{H}_{4} \mathrm{~F}\right)$ or tetrahydromethanopterin $\left(\mathrm{H}_{4} \mathrm{MPT}\right)$, or thiols-glutathione $(\mathrm{GSH})$, mycothiol $(\mathrm{MSH})$, or bacillithiol (BSH) (Figure 2) [22,39-46].

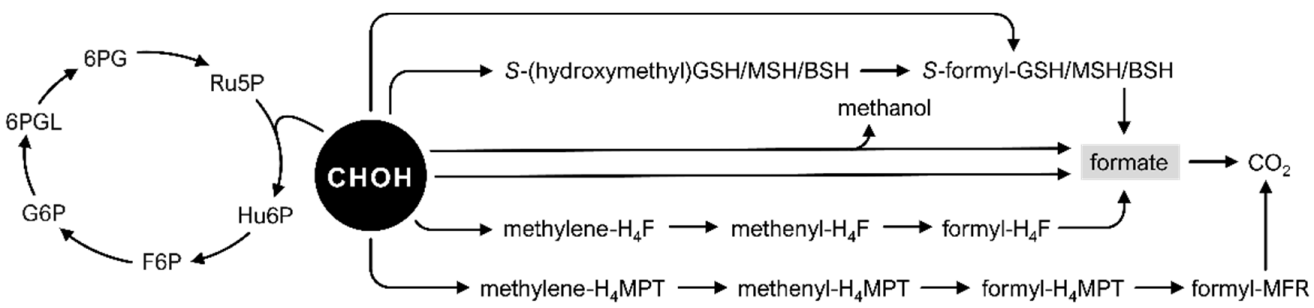

Figure 2. Formaldehyde dissimilation pathways. Schematic view of natural formaldehyde dissimilation pathways mentioned in this review. Metabolites: $\mathrm{CHOH}=$ formaldehyde; $\mathrm{GSH}=$ glutathione; $\mathrm{MSH}=$ mycothiol; $\mathrm{BSH}=$ bacillithiol; $\mathrm{H}_{4} \mathrm{~F}$ = tetrahydrofolate; $\mathrm{H}_{4} \mathrm{MPT}=$ tetrahydromethanopterin; MFR = methanofuran; Ru5P = ribulose 5-phosphate; Hu6P = hexulose 6-phosphate; F6P = fructose 6-phosphate; G6P = glucose 6-phosphate; 6PGL = 6-phospho-glucono-1,5-lactone; 6PG = 6phosphogluconate. Relevant metabolites are highlighted in a grey box.

Among the pterin-dependent pathways, the activity of the $\mathrm{H}_{4} \mathrm{~F}$-dependent one (Figure 2) was detected in B. methanolicus MGA3 (Table 1) [45-47]. After spontaneous condensation of formaldehyde with $\mathrm{H}_{4} \mathrm{~F}$ to form methylene- $\mathrm{H}_{4} \mathrm{~F}$, methylene- $\mathrm{H}_{4} \mathrm{~F}$ is transformed to methenyl- $\mathrm{H}_{4} \mathrm{~F}$ in the reaction catalyzed by methylene- $\mathrm{H}_{4} \mathrm{~F}$ dehydrogenase (Figure 2) [45]. The same enzyme catalyzes the conversion of methenyl- $\mathrm{H}_{4} \mathrm{~F}$ to formyl$\mathrm{H}_{4} \mathrm{~F}$, which is followed by two reactions resulting in the formation of formate and its oxidation to $\mathrm{CO}_{2}$ [45]. While $\mathrm{H}_{4} \mathrm{~F}$-dependent reactions occur in $M$. extorquens AM1, the $\mathrm{H}_{4} \mathrm{~F}$-dependent enzymes are responsible for maintaining high levels of the intermediates necessary to feed the assimilatory serine cycle with formate representing the primary metabolic branch point between assimilation and dissimilation (Section 3.2) $[41,48,49]$. The $\mathrm{H}_{4} \mathrm{MPT}$-dependent dissimilation pathway in M. extorquens AM1 begins with the spontaneous condensation of formaldehyde with $\mathrm{H}_{4} \mathrm{MPT}$ to methylene- $\mathrm{H}_{4} \mathrm{MPT}$, which is accelerated by the formaldehyde-activating enzyme (Fae) (Figure 2) [41,50]. Methylene- $\mathrm{H}_{4} \mathrm{MPT}$ is further converted to methenyl- $\mathrm{H}_{4} \mathrm{MPT}$ in the reaction catalyzed by methylene- $\mathrm{H}_{4} \mathrm{MPT}$ dehydrogenase and followed by several reactions leading to the formation of $\mathrm{CO}_{2}$ [41]. A comprehensive analysis was performed to elucidate the distribution of the $\mathrm{H}_{4} \mathrm{MPT}$ dependent pathway among methylotrophic bacteria, where it was shown that it is present not only in $\alpha$-proteobacteria that possess the serine cycle for formaldehyde assimilation but also methylotrophic $\gamma$ - and $\beta$-proteobacteria, which assimilate formaldehyde through the RuMP cycle (Table 1, Section 3.1) [39,43,44,51,52]. The $\mathrm{H}_{4} \mathrm{MPT}$-dependent formaldehyde dissimilation pathway was detected neither in Amycolatopsis methanolica nor in $B$. methanolicus MGA3 [39].

In the GSH-dependent pathway, formaldehyde binds to reduced GSH, which leads to the creation of $S$-(hydroxymethyl)GSH, and in Paracoccus denitrificans, this spontaneous reaction is accelerated by the glutathione-dependent formaldehyde-activating enzyme (Gfa). However, the presence of Gfa is not essential for the reaction to occur as the GSH-dependent pathway is active in the $g f a$-deficient genetic background [53-56]. S-(hydroxymethyl)GSH is converted to $S$-formyl-GSH by a NAD-GSH-dependent formaldehyde dehydrogenase (GD-Faldh) [40]. S-Formyl-GSH is then hydrolyzed by S-formyl-GSH hydrolase (Fgh) to GSH and formate, with the latter being subsequently oxidized to $\mathrm{CO}_{2}$ (Figure 2) [54]. This pathway is present and functional in different $\alpha$-proteobacteria, for example, Methylobacterium aquaticum 22A, P. denitrificans, Rhodobacter sphaeroides, and Rhodopseudomonas acidophila (Table 1) [40,51,54,57-60]. 
Conversely, the actinobacteria A. methanolica and Rhodococcus erythropolis use an MSHdependent formaldehyde dehydrogenase instead of GD-Faldh, whereas B. methanolicus MGA3 uses BSH as a cofactor for the oxidation of formaldehyde via $S$-formyl-BSH (Table 1, Figure 2) [45,61-63]. In B. methanolicus MGA3, this pathway is activated by switching from nonmethylotrophic to methylotrophic growth [45].

In H. zavarzinii ZV580 and Methylococcus capsulatus Bath, the oxidation of formaldehyde can be catalyzed directly by dye-linked dehydrogenases (DL-Faldh), which most commonly use pyrroloquinoline quinone (PQQ) as their cofactor [64,65]. The PQQ-containing formaldehyde dehydrogenase from $M$. capsulatus Bath is a membrane-bound enzyme coupled to the electron transport chain via a $b$-type cytochrome or a quinone. Furthermore, the PQQ-lanthanide (Ln)-dependent methanol dehydrogenases (Mdh) XoxF1 from M. extorquens AM1, M. aquaticum 22A, or Methylacidiphilum fumariolicum SolV catalyze the oxidation of formaldehyde in vitro [51,66-68]. However, while in M. aquaticum 22A XoxF1 was shown to be functional as a formaldehyde detoxification strategy in vivo, the $M$. extorquens AM1-derived XoxF1 does not exhibit that function, and therefore $M$. extorquens AM1 relies on the activity of the $\mathrm{H}_{4} \mathrm{MPT}$-dependent pathway to maintain formaldehyde levels below the toxicity threshold [51,68]. Strikingly, M. extorquens AM1-derived XoxF1 plays a role in regulating its methanol metabolism (Section 4) [69].

Table 1. List of formaldehyde dissimilation pathways in methylotrophic bacteria.

\begin{tabular}{|c|c|c|c|}
\hline Pathway $^{1}$ & Characteristic & Example Organism & References \\
\hline $\mathrm{H}_{4} \mathrm{~F}$-dependent pathway & $\begin{array}{l}\text { Linear formaldehyde } \\
\text { dissimilation pathway, requires } \\
\text { pterin cofactor } \mathrm{H}_{4} \mathrm{~F}\end{array}$ & B. methanolicus MGA3 & [45-47] \\
\hline $\mathrm{H}_{4} \mathrm{MPT}$-dependent pathway & $\begin{array}{l}\text { Linear formaldehyde } \\
\text { dissimilation pathway, requires } \\
\text { pterin cofactor } \mathrm{H}_{4} \mathrm{MPT}\end{array}$ & $\begin{array}{c}\text { M. extorquens AM1, } \\
\text { Methylobacterium } \\
\text { organophilum XX, } \\
\text { M. aquaticum 22A, } \\
\text { Methylobacterium segetis 17J42-1 }{ }^{\mathrm{T}} \text {, } \\
\text { Hyphomicrobium methylovorum } \\
\text { GM2, Hyphomicrobium } \\
\text { zavarzinii ZV580, Methylosinus } \\
\text { trichosporium OB3b, M. capsulatus } \\
\text { Bath, Methylococcus thermophilus } \\
\text { IIIp, Methylomicrobium album BG8, } \\
\text { Methylomonas rubra 15sh, M. } \\
\text { flagellatus KT, Methylophilus } \\
\text { methylotrophus AS }\end{array}$ & {$[39,41-44,51]$} \\
\hline GSH-dependent pathway & $\begin{array}{c}\text { Linear formaldehyde } \\
\text { dissimilation pathway, requires } \\
\text { thiol cofactor GSH }\end{array}$ & $\begin{array}{l}\text { M. aquaticum 22A, P. denitrificans, } \\
\text { R. sphaeroides, } R \text {. acidophila }\end{array}$ & {$[40,51,54,57-60]$} \\
\hline MSH-dependent pathway & $\begin{array}{l}\text { Linear formaldehyde } \\
\text { dissimilation pathway, requires } \\
\text { thiol cofactor MSH }\end{array}$ & $\begin{array}{l}\text { A. methanolica, } \\
\text { R. erythropolis }\end{array}$ & [61-63] \\
\hline BSH-dependent pathway & $\begin{array}{c}\text { Linear formaldehyde } \\
\text { dissimilation pathway, requires } \\
\text { thiol cofactor BSH }\end{array}$ & B. methanolicus MGA3 & [45] \\
\hline $\begin{array}{l}\text { DL-Faldh-mediated formaldehyde } \\
\text { dissimilation process }\end{array}$ & $\begin{array}{l}\text { Formaldehyde dissimilation } \\
\text { process, relies on activity of } \\
\text { DL-Faldh; membrane-associated } \\
\text { in } M \text {. capsulatus Bath }\end{array}$ & $\begin{array}{l}\text { H. zavarzinii ZV580, } \\
\text { M. capsulatus Bath }\end{array}$ & {$[64,65]$} \\
\hline $\begin{array}{l}\text { PQQ-Ln-dependent formaldehyde } \\
\text { dissimilation process }\end{array}$ & $\begin{array}{l}\text { Formaldehyde oxidation by a } \\
\text { PQQ-Ln-dependent Mdh (XoxF1) }\end{array}$ & $\begin{array}{l}\text { M. extorquens AM1, M. aquaticum } \\
\text { 22A, M. fumariolicum SolV }\end{array}$ & {$[51,66-68]$} \\
\hline Dissimilatory variant of RuMP cycle & $\begin{array}{l}\text { Cyclic formaldehyde } \\
\text { dissimilation pathway }\end{array}$ & $\begin{array}{l}\text { B. methanolicus MGA3, } M \text {. } \\
\text { flagellatus KT, M. sulfidovorans }\end{array}$ & {$[22,44,70]$} \\
\hline
\end{tabular}

${ }^{1}$ Dissimilatory pathways mentioned in this review, their characteristics and example organisms.

As mentioned above, formaldehyde can be dissimilated not only through oxidation in linear dissimilation pathways but also through the reaction with sugar phosphates in 
a cyclic variant of the RuMP cycle known as cyclic dissimilation or oxidative pentose phosphate pathway (PPP) (Figure 2) [22,44]. This cycle shares the activity of 3-hexulose-6phosphate synthase (Hps) and 6-phospho-3-hexuloisomerase (Phi) with the formaldehyde assimilation pathway (Section 3.1). In the first step, Hps catalyzes the condensation between formaldehyde and ribulose 5-phosphate (Ru5P) to hexulose 6-phosphate (Hu6P), which is later isomerized into fructose 6-phosphate (F6P) in a reaction catalyzed by Phi [20,22]. In the subsequent reactions, the sugar phosphates undergo a series of chemical transformations to 6-phosphogluconate (6PG) followed by its decarboxylation leading to regeneration of Ru5P (Figure 2) [20]. To our knowledge, this cycle was only found to be active in methylotrophs that utilize the RuMP cycle for formaldehyde assimilation, for example, B. methanolicus MGA3, Methylobacillus flagellatus KT, and Methylophaga sulfidovorans (Table 1) [22,44,70]. The outcome of the cyclic dissimilatory pathway is not exclusively Ru5P regeneration, as it also contributes to formaldehyde detoxification and generation of both energy and reducing power [29]. Interestingly, in M. flagellatus KT, this dissimilatory cycle is essential for growth on methanol and probably serves as the primary energy source [44]. Likewise, cyclic dissimilation is one of the main suppliers of NADPH in B. methanolicus MGA3 under methylotrophic conditions, highlighting its essential role in cofactor regeneration [71]. Most heterotrophic bacteria rely on the tricarboxylic acid (TCA) cycle and electron transport chain to meet the latter requirement. However, some methylotrophs do not need a complete TCA to fulfil their energy requirements; thus, the cyclic dissimilatory pathway has been proposed as a substitute to the TCA cycle for the generation of reducing power [72]. Taken together, this shows how intertwined $\mathrm{C} 1$ metabolic pathways are and that many considerations need to be made while designing pathways to establish synthetic methylotrophy and choosing enzymes with respective activities, which is described in more detail in Section 3.

\subsection{Modification of Formaldehyde Dissimilation Pathways in Nonmethylotrophic Bacteria Is a Prerequisite for Synthetic Methylotrophy}

As mentioned before, formaldehyde dissimilation strategies are ubiquitous in all living organisms. In Section 2.1, we presented examples of such pathways in methylotrophic bacteria where the control of formaldehyde intracellular concentration is particularly important because it is formed as a central metabolite in carbon assimilation processes. Interestingly, formaldehyde dissimilation in nonmethylotrophic bacteria shares multiple enzymes with methylotrophic routes. For instance, the MSH-dependent and the cyclic formaldehyde dissimilation pathway described for methylotrophic bacteria are also present in the nonmethylotrophs Mycobacterium smegmatis and Burkholderia cepacia TM1 (Table 2) [73,74]. In the latter, the activity of Hps and Phi increases during vanillic acid-based growth compared with other carbon sources, indicating that this pathway is involved in the dissimilation of formaldehyde released during vanillic acid degradation via demethylation [74]. Moreover, many nonmethylotrophs such as P. putida, Pseudomonas aeruginosa, and Burkholderia fungorum LB400 possess GSH-independent formaldehyde dissimilation pathways that involve a zinc-containing Faldh utilizing $\mathrm{NAD}^{+}$as an electron carrier (Table 2) [75-78]. In fact, B. fungorum LB400 has two more formaldehyde oxidation pathways, GSH- and $\mathrm{H}_{4}$ MPT-dependent (Table 2) [76]. A relatively uncommon formaldehyde detoxification pathway is based on the activity of formaldehyde dismutase present in P. putida that catalyzes the dismutation of formaldehyde, leading to the formation of equimolar amounts of the corresponding methanol and formate (Table 2, Figure 2) [79]. P. putida acquires its resistance to high concentrations of formaldehyde up to $60 \mathrm{mM}$ through the activity of formaldehyde dismutase, which is induced by supplementation of formaldehyde to the growth medium [79]. Interestingly, putative formaldehyde dismutases in methylotrophic A. methanolica and Mycobacterium gastri seem not to be involved in formaldehyde detoxification and appear to be active as Mdh, responsible for methanol oxidation [80]. Due to the astounding prevalence and diversity of the formaldehyde dissimilation pathways in nonmethylotrophic bacteria, in this Section, we will focus particularly on three strains: B. subtilis, E. coli, and C. glutamicum, of which E. coli and C. glutamicum have been used as 
predominant hosts for synthetic methylotrophy and B. subtilis has traditionally been used as a gene donor to create synthetic assimilation pathways.

B. subtilis, a cell factory used for microbial production of chemicals, enzymes, and antimicrobial materials, tolerates relatively high doses of formaldehyde with 1-2 mM formaldehyde leading to decreased growth rate but not affecting the number of viable cells [81]. Formaldehyde kills B. subtilis spores through DNA damage caused by proteinDNA cross-linking [82]. To circumvent this, the $a / b$-type small, acid-soluble spore proteins (SASP) and $\beta$-subunit of RNA polymerase constitute two active mechanisms in spores as protection against formaldehyde toxicity and mutagenesis [82,83]. In vegetative cells, two formaldehyde dissimilation pathways are active, a thiol-dependent formaldehyde dissimilation pathway and the dissimilatory variant of the RuMP cycle described in Section 2.1 (Table 2) [81,84-86]. The expression of $a d h A$, encoding a thiol-dependent aldehyde dehydrogenase, is induced by formaldehyde and regulated by AdhR (Section 4) [81]. AdhA has not been functionally characterized yet; however, based on the fact that BSH is the major low molecular mass thiol produced by B. subtilis, it is safe to assume that the formaldehyde dehydrogenase in this bacterium is BSH-dependent $[84,87]$. Formaldehyde induces the expression of two genes, $h x l A$ and $h x l B$, that encode Hps and Phi, respectively, essential in formaldehyde dissimilation in B. subtilis [85]. Interestingly, the cyclic dissimilation pathway in B. subtilis shares the activity of Hps and Phi with both cyclic dissimilation and assimilation pathways present in methylotrophs (Sections 2.1 and 3.1); however, the fate of F6P is different in these two pathways. Because of this, already more than two decades ago, Yasueda et al. suggested that due to its genetic makeup and presence of Hps-Phi activity, the establishment of synthetic methylotrophy in B. subtilis requires theoretically only the additional activity of a heterologous Mdh [85]. Indeed, this approach has been applied very recently as a basis to develop the first methanol-dependent $B$. subtilis [25]. Furthermore, $h x l A$ and $h x l B$ derived from this bacterium have been routinely applied for heterologous expression in the industrial workhorse for amino acid production C. glutamicum in order to drive formaldehyde fixation to F6P in attempts at building synthetic methylotrophy $[38,88,89]$. In this instance, F6P produced by the action of $h x l A$ and $h x l B$ enters the process of assimilation catalyzed by enzymes of the nonoxidative PPP, which ultimately leads to methanol-dependent growth and incorporation of methanol-derived carbon (Section 3.1) [88,89].

C. glutamicum has two pathways leading to formaldehyde dissimilation, either through direct oxidation to formate by the acetaldehyde dehydrogenase (Ald) or through a series of steps that start with a spontaneous reaction with MSH to form S-(hydroxymethyl)MSH (Table 2, Figure 2) $[90,91]$. For the latter pathway, in the following step $S$-(hydroxymethyl) MSH is oxidized to $S$-formyl-MSH in a reaction catalyzed by AdhE, and then S-formylMSH is spontaneously hydrolyzed to MSH and formate [90-92]. Finally, formate formed by either of the two dissimilation pathways is oxidized to $\mathrm{CO}_{2}$ by the formate dehydrogenase FdhF with the contribution of two additional genes, which are presumed to be involved in formate oxidation [90-92]. Both Ald and AdhE encoding genes, either single or in combination, have been deleted in C. glutamicum in attempts to redirect metabolic flux from formaldehyde dissimilation to assimilation during the establishment of synthetic methylotrophy [88-90,93-95]. However, deletion of ald and adhE can lead to adverse effects such as reduced methanol consumption rate, slow growth and a lowered final cell dry weight as compared to the strains harboring ald and adhE, most probably due to accumulation of formaldehyde above the toxicity threshold [88]. 
Table 2. List of formaldehyde dissimilation pathways in nonmethylotrophic bacteria.

\begin{tabular}{|c|c|c|c|}
\hline Pathway $^{1}$ & Characteristic & Example Organism & Reference \\
\hline $\mathrm{H}_{4} \mathrm{MPT}$-dependent pathway & $\begin{array}{l}\text { Linear formaldehyde } \\
\text { dissimilation pathway, requires } \\
\text { pterin cofactor } \mathrm{H}_{4} \mathrm{MPT}\end{array}$ & B. fungorum LB400 & [76] \\
\hline GSH-dependent pathway & $\begin{array}{c}\text { Linear formaldehyde } \\
\text { dissimilation pathway, requires } \\
\text { thiol cofactor GSH }\end{array}$ & $\begin{array}{l}\text { E. coli, } \\
\text { B. fungorum LB400 }\end{array}$ & {$[76,96-98]$} \\
\hline BSH-dependent pathway & $\begin{array}{c}\text { Linear formaldehyde } \\
\text { dissimilation pathway, requires } \\
\text { thiol cofactor BSH }\end{array}$ & B. subtilis & {$[81,84]$} \\
\hline MSH-dependent pathway & $\begin{array}{c}\text { Linear formaldehyde } \\
\text { dissimilation pathway, requires } \\
\text { thiol cofactor MSH }\end{array}$ & C. glutamicum, M. smegmatis & {$[73,90,91]$} \\
\hline Faldh dissimilation process & $\begin{array}{l}\text { Zinc-dependent formaldehyde } \\
\text { oxidation pathway, relies on } \\
\text { activity of Faldh that utilizes } \\
\text { NAD+ as an electron acceptor }\end{array}$ & $\begin{array}{l}\text { P. putida, P. aeruginosa, } \\
\text { B. fungorum LB400 }\end{array}$ & {$[75-78]$} \\
\hline $\begin{array}{l}\text { Formaldehyde dismutase-mediated } \\
\text { dissimilation process }\end{array}$ & $\begin{array}{l}\text { Formaldehyde dissimilation } \\
\text { based on the activity of } \\
\text { formaldehyde dismutase, leading } \\
\text { to the formation of equimolar } \\
\text { amounts of methanol and formate }\end{array}$ & P. putida & [79] \\
\hline Ald-mediated dissimilation process & $\begin{array}{l}\text { Formaldehyde dissimilation } \\
\text { through direct oxidation to } \\
\text { formate by Ald }\end{array}$ & C. glutamicum & {$[38,90,91]$} \\
\hline Dissimilatory variant of RuMP cycle & $\begin{array}{l}\text { Cyclic formaldehyde } \\
\text { dissimilation pathway }\end{array}$ & B. subtilis, B. cepacia & {$[74,85,86]$} \\
\hline
\end{tabular}

${ }^{1}$ Dissimilatory pathways mentioned in this review, their characteristics and example organisms.

The main formaldehyde dissimilation pathway in E. coli, a prominent host for natural product biosynthesis, is GSH-dependent and composed of GD-Faldh (encoded by frm $A$ ) and Fgh (encoded by frmB) (Table 2) [37,96-100]. The genes encoding those two enzymes are clustered and expressed in an operon together with the regulator-encoding gene frm $R$ (Section 4). It seems that FrmA is not the unique GD-Faldh in E. coli, as it was shown that production of formate also occurs in the $\triangle$ frmA E. coli strain. It was suggested that a promiscuous alcohol dehydrogenase could replace GD-Faldh activity in the conversion of formaldehyde to S-formyl-GSH, which is then converted to formate by Fgh (Figure 2) [101]. Moreover, two paralogous genes encode Fgh: frmB and yeiG. While single deletion of each of those genes did not affect the growth of $E$. coli in the presence of formaldehyde, the double-mutant strain of $E$. coli showed a reduced growth rate in such conditions [99]. In $E$. coli cells, yeiG was found to be a constitutively expressed gene, while the expression of $f r m B$ was a part of the frmRAB operon $[98,99]$. This endogenous system was, in fact, used to achieve synthetic methylotrophy through the oxidation of formaldehyde to formate in E. coli combined with formate assimilation by diverse pathways described in more detail in Section 3.2. As mentioned before, the deletion of native formaldehyde dissimilation pathways is a relevant strategy to redirect metabolic flux towards formaldehyde assimilation in synthetic methylotrophs. The deletion of frm $A$ or its mutations occurring during adaptive laboratory evolution (ALE) experiments were achieved in several studies to establish synthetic methylotrophy in E. coli, which indicates that the conservation of formaldehyde is essential for growth on methylotrophic substrates [27,101-121]. 


\section{Formaldehyde Assimilation in Methylotrophic Bacteria Is an Inspiration for the Creation of Synthetic Methylotrophs}

A detailed understanding of formaldehyde assimilation pathways in methylotrophic bacteria is essential for establishing synthetic methylotrophy. In this Section, we describe in detail the RuMP and the serine cycle as natural formaldehyde assimilation pathways and show several attempts at achieving synthetic methylotrophy using these pathways or their derivatives, as well as the engineering work leading to novel assimilation pathways.

\subsection{The RuMP Cycle and Its Adaptation to Synthetic Methylotrophy}

The RuMP cycle is present in bacteria such as B. methanolicus MGA3, M. gastri MB19, Nocardia sp. 239, A. methanolica, M. capsulatus, Methylomonas aminofaciens 77a, and M. flagellatus KT [122-129]. Formaldehyde assimilation through the RuMP cycle can be divided into three phases: fixation, cleavage, and rearrangement [20]. As aforementioned, in the fixation phase, Hps catalyzes the condensation between formaldehyde and Ru5P, resulting in the formation of Hu6P (Figure 3) [20]. Hu6P is then isomerized into F6P in a reaction catalyzed by Phi [20]. Subsequently, during the cleavage phase, F6P is phosphorylated to fructose 1,6-bisphosphate (FBP), which is then cleaved to glyceraldehyde 3-phosphate (GAP) and dihydroxyacetone phosphate (DHAP) in the reaction catalyzed by FBP-aldolase [20]. GAP, in turn, can ultimately be converted to acetyl-CoA with pyruvate as an intermediate (Figure 3) [20]. The cleavage phase of the RuMP cycle is followed by the rearrangement phase undergoing the nonoxidative branch of the PPP, with two variants: the fructose 1,6-bisphosphate aldolase/transaldolase ( $\mathrm{FBPa} / \mathrm{Ta})$ variant and the fructose 1,6-bisphosphate aldolase/sedoheptulose-1,7-bisphosphatase (FBPa/SBPase) variant $[20,22,130,131]$. In both variants of the pathway, sedoheptulose 7-phosphate (S7P) and GAP molecules are converted to ribose 5-phosphate (Ri5P) and xylulose 5-phosphate (Xu5P) through the activity of transketolase (Tkt) [20]. In the last step of the RuMP cycle, $\mathrm{Ru} 5 \mathrm{P}$ is restored either from Ri5P through the activity of Ri5P isomerase (Rpi) or from Xu5P through the activity of Ru5P epimerase (Rpe; Figure 3) [20]. The SBPase variant of the RuMP cycle was shown to be active in the methylotrophic bacterium B. methanolicus MGA3 through a study of enzymatic activity and a metabolic flux analysis [71,132]. Nevertheless, according to the fluxomics study conducted by Delépine et al., it cannot be excluded that the Ta variant is operating in parallel. In fact, it was proposed that a parallel activity of both RuMP cycle variants would be beneficial for the growth of B. methanolicus MGA3 on a mixture of different carbon sources [71]. Moreover, a recent study detected Ta activity in both B. methanolicus MGA3 and PB1 strains and suggested that they may as well use the Ta variant of the RuMP cycle for formaldehyde assimilation [132-134].

The RuMP cycle serves as a foundation in the design of synthetic methylotrophy approaches. In the case of synthetic methanol utilization, the common scheme for the implementation of methylotrophy in nonmethylotrophs is the introduction of a minimal set of enzymes: a combination of Mdh that catalyzes the oxidation of methanol to formaldehyde, and Hps and Phi for a two-step irreversible condensation of formaldehyde with Ru5P, following isomerization to form F6P. Mdh that is used to source formaldehyde in the methanol oxidation reaction exhibits formaldehyde reductase activity, which is highly favoured compared to methanol oxidation [135]. For this reason, rapid formaldehyde condensation with Ru5P catalysed by the activity of Hps is necessary to pull the carbon flux towards formaldehyde assimilation. To favour formaldehyde condensation with Ru5P, the effect of spaces between the enzymes and their substrates was considered [103,136,137]. In order to decrease the distance between formaldehyde and Hps, use of the cascade reactions by $\mathrm{Mdh}, \mathrm{Hps}$, and Phi was achieved by creating supramolecular enzyme complexes resulting from the fusion of those proteins $[103,136]$. Accordingly, an in vitro fusion protein system consisting of the $\mathrm{NAD}^{+}$-dependent Mdh from B. methanolicus MGA3 and the Hps-Phi from $M$. gastri enhanced methanol conversion to F6P by promoting efficient formaldehyde channelling through the pathway rather than back to methanol [103]. Likewise, a multienzyme complex composed of the $\mathrm{NAD}^{+}$-dependent Mdh from Geobacillus stearothermophilus and 
Hps-Phi from B. methanolicus MGA3 showed elevated methanol oxidation activity and F6P formation efficiency [136]. The fate of F6P can be divergent in the bacterial cell; it can either enter the cyclic dissimilatory pathway (Section 2, Figure 2) or be phosphorylated to FBP in a reaction catalyzed by 6-phosphofructokinase, entering the assimilatory pathway (Figure 3). The importance of the deregulation of native formaldehyde dissimilation pathways in strains used as hosts for synthetic methylotrophy to direct the carbon flux towards formaldehyde fixation is discussed in Section 2.
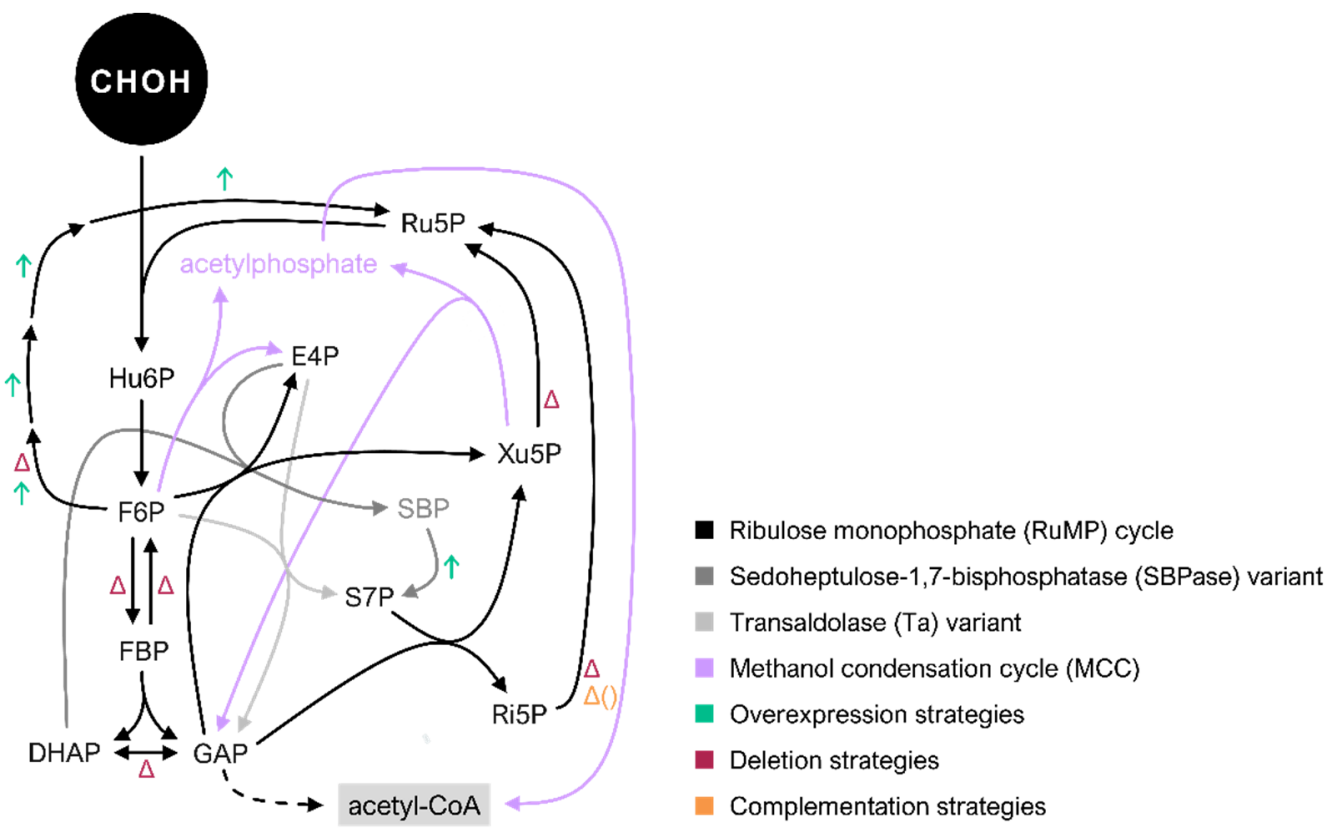

Figure 3. The RuMP cycle and its modifications. Schematic representation of the RuMP cycle (black) with its SBPase variant (dark grey), Ta variant (light grey), and the synthetic biocatalytic MCC (violet). Overexpression strategies are depicted in green, deletion strategies in red, and complementation strategies in orange. Dashed arrows represent multiple reactions. Metabolites: $\mathrm{CHOH}=$ formaldehyde; Ru5P = ribulose 5-phosphate; Hu6P = hexulose 6-phosphate; E4P = erythrose 4-phosphate; F6P = fructose 6-phosphate; FBP = fructose 1,6-bisphosphate; DHAP = dihydroxyacetone phosphate; $\mathrm{GAP}=$ glyceraldehyde 3-phosphate; S7P = sedoheptulose 7-phosphate; SBP = sedoheptulose 1,7bisphosphate; Ri5P = ribose 5-phosphate; $\mathrm{Xu} 5 \mathrm{P}=$ xylulose 5-phosphate. Relevant metabolites are highlighted in a grey box. Unspecified metabolites leading to Ru5P regeneration through the linear formaldehyde dissimilatory pathway are detailed in Figure 2.

While it was shown that the minimal catalytic requirement to establish synthetic methylotrophy in microbial species such as E. coli and C. glutamicum is the introduction of methanol oxidation to formaldehyde by Mdh and its following fixation by Hps and Phi, several additional considerations need to be taken into account. To sustain continuous formaldehyde assimilation, the RuMP cycle must continually regenerate the cosubstrate of Hps, Ru5P. Indeed, the overexpression of genes coding for enzymes that participate in the nonoxidative PPP improved formaldehyde assimilation in E. coli [119]. Similarly, seeking to address insufficient Ru5P regeneration in synthetic methylotrophic E. coli, Woolston et al. activated the SBPase variant of RuMP in E. coli by overexpression of its native $g l p X$ gene [115]. That, in combination with the supplementation of iodoacetate, an inhibitor of GAP dehydrogenase in lower glycolysis, resulted in increased Ru5P, F6P, and S7P concentrations in E. coli cells, which consequently accelerated formaldehyde assimilation [115]. In fact, in a recent work that employed a previously constructed methanol-dependent C. glutamicum strain by Tuyishime et al., further ALE experiments in high methanol concentration led to downregulation of glycolysis encoding genes, which improved the regeneration of Ru5P [94,138]. 
Furthermore, towards the improvement of Ru5P regeneration in the synthetic methylotrophy pathway, the disruption of genes encoding key nonoxidative PPP enzymes such as Rpi or Rpe reroutes the catabolism of cosubstrates xylose or ribose, respectively, to Ru5P formation $[89,94,116,139]$. The deletion of $p g i$ in $E$. coli expressing $h x l A B$ derived from $B$. subtilis leads to rerouting glucose carbon flux through the oxidative PPP during methanol co-consumption with glucose [119]. The only successful attempt at autonomous synthetic methylotrophy to date was based on the RuMP cycle [27]. First, the E. coli BW25113 background (with a high mutation frequency) was forced towards methanol auxotrophy through deletion of $r p i A B$, provision of xylose as a cosubstrate and heterologous expression of synthetic methylotrophy operon [27]. This strain was evolved for 20 generations, which resulted in the inactivation of genes that would have otherwise led to NADH excess and a loss in formaldehyde levels through its oxidation [27]. Following this, the ensemble modelling for robustness analysis (EMRA) was employed, a tool that suggests enzymes that require up or down-regulation in a given system to avoid the instability caused by kinetic traps, which endorsed the subsequent deletion of $p f k A$ encoding phosphofructokinase and replacement of native gapA encoding GAP dehydrogenase for the E. coli BL21-derived gapC, which possesses only $40 \%$ of GapA activity $[27,140]$. That, in addition to rpiA complementation to promote utilization of methanol as the sole carbon source and several nutrient weaning strategies, resulted in a successfully generated synthetic methylotroph, albeit with a very low growth rate and biomass yield [27]. It could be observed that a shortage of Ru5P results in formaldehyde accumulation, which in turn leads to formaldehyde-induced DNA-protein cross-linking and, eventually, cell death during the stationary phase [27]. By further ALE of the first synthetic methylotroph, that effect caused by formaldehyde accumulation could be solved by insertion sequence-mediated copy number variations, i.e., as ALE progressed, the copy number of a region spanning 70 kilobases, encompassing the originally introduced synthetic methylotrophy operon, increased [27]. The dynamic adaptation resulted in a final synthetic methylotrophic strain that displayed a doubling time of $8.5 \mathrm{~h}$ (growth rate of $0.09 \mathrm{~h}^{-1}$ ) and a maximum optical density at $600 \mathrm{~nm}$ of 2 with methanol as sole carbon source [27].

The aforementioned strain also benefited from an ALE-derived 12-basepair deletion in $p g i$, which increased its activity and presumably diverted flux to the oxidative PPP, thus generating additional NADPH for growth [27]. Building on the experience with the optimization through ALE of strains coutilizing methanol and RuMP cycle metabolites, an improved strategy was developed where deletion of RuMP cycle genes is not required to drive co-consumption [141]. In extensive flux balance analysis (FBA), the deletion targets were predicted to obtain genetic backgrounds of $E$. coli that support growth on methanol or methanol together with a multicarbon cosubstrate but not on such cosubstrate alone [141]. Furthermore, genetic makeups lacking the potential for pure methylotrophic growth due to a compromised RuMP cycle were excluded [141]. Considering further selection parameters, two targets for deletion were chosen: $f b p$ encoding fructose-1,6-bisphosphatase and tpiA encoding triosephosphate isomerase [141]. Deleting each target together with frm and plasmid-based expression of $m d h, h p s$, and $p h i$ led to the creation of strains that required methanol for growth on pyruvate and are ideal candidates for evolution towards a fully methylotrophic E. coli [141].

Balancing metabolic reactions in potential synthetic methylotrophs that do not naturally possess the metabolic landscape present in naturally methylotrophic microorganisms has proven to be challenging. Energy and carbon balance between formaldehyde assimilation and dissimilation in methylotrophs has been gradually optimized through evolution; therefore, artificial introduction of formaldehyde assimilation into nonmethylotrophic species is a desired yet laborious endeavour. For this reason, rather than the plain introduction of formaldehyde assimilation pathways into heterologous hosts, targeted redesign and optimization is required [34]. Several studies that used ALE to achieve synthetic methylotrophy in E. coli and C. glutamicum revealed causative mutations involved in redox balancing $[106,116,138,142]$. For instance, a mutation was found in the adenylate cyclase 
(cyaA) gene of E. coli [116], CyaA catalyzes the conversion of ATP to cAMP, which subsequently activates the TCA cycle [116]. The deactivation of CyaA results in lower TCA cycle activity, therefore reducing NADH generation by the TCA to balance the NADH generated during exogenous methanol oxidation to formaldehyde by Mdh [116]. In a subsequent $E$. coli work, a mutation was found after ALE in the isocitrate dehydrogenase (icd) gene that reduced Icd activity, which ultimately decreased TCA cycle activity balancing intracellular NADH levels [106]. Similarly, an ALE-derived C. glutamicum strain showed downregulation of the malate dehydrogenase (Maldh) encoding gene, which led to decreased NADH generation through the TCA cycle, confirming what had been previously observed regarding redox balance in an E. coli $\Delta$ maldh strain $[117,138]$. In all three cases, the ALE-derived mutations mimic what has been observed in methylotrophic metabolism, namely low TCA cycle activity.

Another way to reduce NADH accumulation is the introduction of production pathways that consume NADH or the conversion of NADH to NADPH for later use in lysine production $[102,118,143]$. Additionally, lactate dehydrogenase from E. coli was employed as an NADH scavenger to favour the Mdh-mediated forward reaction and prevent formaldehyde reduction [103].

The carbon efficiency of the RuMP cycle is not optimal since three formaldehyde molecules are condensed to pyruvate, which is decarboxylated to form acetyl-CoA and $\mathrm{CO}_{2}$ [20]. On this account, Bogorad et al. have proposed the construction of the methanol condensation cycle (MCC) (Table 3, Figure 3) [144]. The MCC is a carbon conserved and ATP-independent synthetic biocatalytic pathway that uses enzymatic reactions to convert formaldehyde to acetyl-CoA and water [144]. This pathway modifies the RuMP cycle, which is thereby coupled to a synthetic pathway, the nonoxidative glycolysis (NOG) [145]. The initial steps of the MCC are similar to the RuMP cycle: formaldehyde is combined with Ru5P to form Hu6P, which is further isomerized to F6P (Figure 3) [144]. Then, in the native RuMP cycle, F6P is phosphorylated to FBP and later cleaved to GAP and DHAP. In contrast, in the MCC the NOG takes place instead by employing the activity of a phosphoketolase (Pkt) that can cleave F6P to acetylphosphate and erythrose 4-phosphate (E4P), or Xu5P to acetylphosphate and GAP (which will eventually yield E4P) [144-147]. The activity of Pkt conserves ATP by phosphorylating the $\mathrm{C} 2$ keto group cleaved from $\mathrm{F} 6 \mathrm{P}$ or $\mathrm{Xu} 5 \mathrm{P}$ using inorganic phosphate [144]. The produced acetylphosphate can be readily converted to acetyl-CoA by a phosphate acetyltransferase (Pta) [144]. Furthermore, the generated E4P reacts with F6P through a series of reactions belonging to the Ta variant of RuMP cycle to regenerate two molecules of Ru5P and complete the MCC (Figure 3) [144]. By avoiding pyruvate decarboxylation to form acetyl-CoA, no carbon is lost in the MCC, which benefits carbon yields in synthetic methylotrophy and, in turn, enhances bioprocess economics. Indeed, the MCC system was successfully used to convert the C1 compound methanol to the higher-chain alcohols ethanol and $n$-butanol. However, the proof-of-concept has been presented in in vitro experiments and still awaits application in bacterial cells [144].

\subsection{The Serine Cycle and Its Derivatives}

While the RuMP cycle encompasses carbohydrate intermediates, some of which are phosphorylated, the serine cycle requires carboxylic acids and amino acids as intermediates (Table 3) [21]. Formaldehyde enters the serine pathway through methylene- $\mathrm{H}_{4} \mathrm{~F}$ that can be produced in two different routes [20,49]. In the first route, formaldehyde and $\mathrm{H}_{4} \mathrm{~F}$ are spontaneously combined into methylene- $\mathrm{H}_{4} \mathrm{~F}$, whereas in the second route, formaldehyde is converted to formate in reactions catalyzed by methylene $\mathrm{H}_{4} \mathrm{MPT}$-dependent enzymes, which is then converted to methylene- $\mathrm{H}_{4} \mathrm{~F}$ through the activity of $\mathrm{H}_{4} \mathrm{~F}$-dependent enzymes (Figure 4) [49]. While early research suggested higher metabolic flux through the first of those routes, it was later shown that the latter dominates assimilatory flux in M. extorquens AM1 [49,148]. This identifies formate as a metabolic branch point between carbon assimilation and dissimilation pathways in this bacterium (Section 2.1) and highlights the hemiautotrophic nature of the serine cycle where $\mathrm{CO}_{2}$ generated through formate oxidation 
is incorporated into the cycle [49]. The serine pathway begins with the condensation of methylene- $\mathrm{H}_{4} \mathrm{~F}$ and glycine to produce serine in the reaction catalyzed by serine hydroxymethyltransferase (Shmt) (Figure 4) [20]. Serine undergoes several reactions catalyzed successively by serine transhydroxymethylase, serine-glyoxylate aminotransferase, hydroxypyruvate reductase (Hpr), glycerate kinase, and enolase to form phosphoenolpyruvate (PEP), which is then carboxylated to malate in a two-step reaction catalyzed by PEP carboxylase and Maldh [20]. Subsequently, malate thiokinase (Mtk) catalyzes the reaction of malate conversion to malyl-CoA, which is thereafter cleaved to form glyoxylate and acetyl-CoA in the reaction catalyzed by malyl-CoA lyase $(\mathrm{Mcl})$ [20]. Glyoxylate is converted to glycine in the following step, and thus the serine cycle is completed (Figure 4) [149].

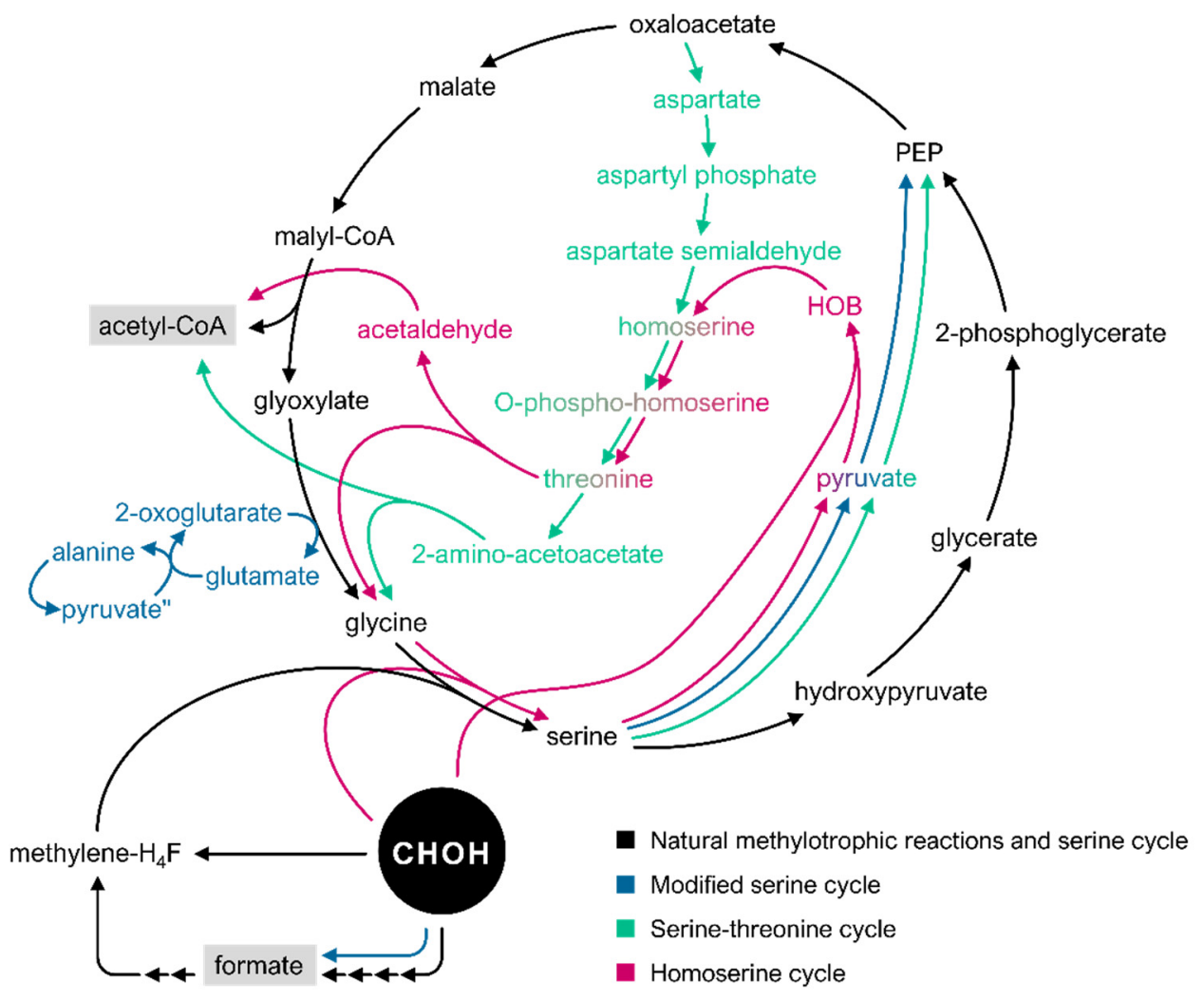

Figure 4. The serine cycle and its modifications. Schematic overview of natural methylotrophic reactions and the serine cycle (black) and its modifications: the modified serine cycle (blue), the serine-threonine cycle (green) and the homoserine cycle (pink). Metabolites: $\mathrm{CHOH}=$ formaldehyde; $\mathrm{PEP}=$ phosphoenolpyruvate; $\mathrm{HOB}=4$-hydroxy-2-oxobutanoate; $\mathrm{H}_{4} \mathrm{~F}=$ tetrahydrofolate. Some metabolites were duplicated for clearer visualization and are indicated with quotation marks ("). Relevant metabolites are highlighted in a grey box. Unspecified metabolites leading to methylene- $\mathrm{H}_{4} \mathrm{~F}$ are part of linear formaldehyde dissimilation and are detailed in Figure 2.

Theoretically, the serine cycle leads to a $100 \%$ carbon yield (the produced glyoxylate eventually regenerates glycine) compared with the RuMP cycle, which has a theoretical carbon yield of $67 \%$ due to decarboxylation steps (for each acetyl-CoA synthesized, one molecule of carbon is lost) [34]. Therefore, the serine cycle exhibits a clear asset chemical production of higher carbon compounds such as ethanol, acetone, butyric acid, or terpenoids, with the latter being naturally produced by the serine cycle-utilizing methylotroph M. extorquens AM1 [34,150]. Although the MCC pathway successfully circumvents carbon loss in the native RuMP cycle, it is yet to be implemented in vivo. The main advantage of the RuMP cycle lies, however, in its energetic efficiency: while NADH and ATP are generated through the RuMP cycle, they are required to drive the process in the serine cycle $[34,36]$. This is the central reason behind focusing on the RuMP cycle for the 
majority of synthetic methylotrophy efforts [36]. In addition to this, the RuMP cycle differs from widespread sugar metabolism by only a couple of genes: most nonmethylotrophs possess the required enzymes involved in F6P cleavage and $\mathrm{Ru} 5 \mathrm{P}$ rearrangement through the PPP, making the introduction of the missing RuMP cycle modules for formaldehyde fixation much simpler than the several reactions required for transfer of the entire serine cycle $[27,34]$. Nevertheless, since the achievement of autonomous methylotrophy using the RuMP cycle approach has had limited success, the development of alternative pathways based on the serine cycle has been pursued [36].

Table 3. List of native formaldehyde assimilation pathways in methylotrophic bacteria and their modifications.

\begin{tabular}{|c|c|c|c|}
\hline Pathway $^{1}$ & Characteristic & Example Organism & Reference \\
\hline \multicolumn{4}{|c|}{ Native pathways } \\
\hline RuMP cycle & $\begin{array}{l}\text { Cyclic formaldehyde assimilation } \\
\text { pathway; formaldehyde enters } \\
\text { the RuMP cycle through } \\
\text { condensation with Ru5P }\end{array}$ & $\begin{array}{l}\text { B. methanolicus MGA3, M. gastri } \\
\text { MB19, Nocardia sp. 239, A. } \\
\text { methanolica, M. capsulatus, } M \text {. } \\
\text { aminofaciens 77a, M. flagellatus KT }\end{array}$ & {$[122-129,132-134]$} \\
\hline Serine cycle & $\begin{array}{l}\text { Cyclic formaldehyde assimilation } \\
\text { pathway; formaldehyde enters the } \\
\text { pathway through methylene- } \mathrm{H}_{4} \mathrm{~F}\end{array}$ & $\begin{array}{l}\text { M. extorquens } \mathrm{AM} 1, M . \\
\text { organophilum } \mathrm{XX}, \mathrm{H} \text {. } \\
\text { methylovorum } \mathrm{GM} 2, M \text {. } \\
\text { trichosporium } \mathrm{OB} 3 \mathrm{~b}\end{array}$ & {$[20,39]$} \\
\hline \multicolumn{4}{|c|}{ Modified pathways } \\
\hline MCC & $\begin{array}{l}\text { Modified RuMP cycle; synthetic } \\
\text { biocatalytic MCC; no carbon loss }\end{array}$ & Has not been applied in vivo yet & [144] \\
\hline Modified serine cycle & $\begin{array}{l}\text { Simplified variant of the serine } \\
\text { cycle which uses one step for the } \\
\text { oxidation of formaldehyde } \\
\text { instead of four in the native serine } \\
\text { pathway; avoids the use of the } \\
\text { Hpr route by glyoxylate } \\
\text { transamination with alanine to } \\
\text { form glycine }\end{array}$ & E.coli & [151] \\
\hline Serine-threonine cycle & $\begin{array}{l}\text { Synthetic variant of the serine } \\
\text { cycle; aims to avoid interference } \\
\text { with central metabolic fluxes; } \\
\text { circumvents the formation of } \\
\text { hydroxypyruvate as intermediate; } \\
\text { further recycling of glycine via } \\
\text { the threonine biosynthesis and } \\
\text { cleavage system }\end{array}$ & E. coli & [152] \\
\hline Homoserine cycle & $\begin{array}{l}\text { Modified variant of the serine } \\
\text { cycle; glycine is directly } \\
\text { condensed with formaldehyde to } \\
\text { generate serine; aims to avoid the } \\
\text { competition of flux between the } \\
\text { pathway reactions and those of } \\
\text { the central metabolism; reduction } \\
\text { of thermodynamic disadvantages } \\
\text { of the natural serine cycle; } \mathrm{CO}_{2} \\
\text { fixation is avoided }\end{array}$ & E. coli & [110] \\
\hline
\end{tabular}

${ }^{1}$ Assimilatory pathways mentioned in this review, their characteristics and example organisms.

One such pathway is the modified serine cycle (Table 3, Figure 4) [151]. In developing this alternative pathway, the goal was two-fold: to reduce the length and complexity of the natural serine cycle and to avoid the deleterious effect of native Hpr in the chosen E. coli 
host [151]. To achieve the first goal, the modified serine cycle uses heterologous Faldh from P. putida to catalyze the oxidation of formaldehyde to formate in a single reaction, thus simplifying the four-step oxidation process present in the native pathway (Figure 4) [151]. For the second goal, since side reactivity of Hpr drains intermediate glyoxylate to form glycolate irreversibly at higher catalytic efficiency than it converts hydroxypyruvate to glycerate, the use of the Hpr route was avoided completely [151]. To achieve this, instead of using serine as an amino group donor to convert glyoxylate to glycine, glyoxylate is transaminated with alanine to form glycine in a reaction catalyzed by alanine-glyoxylate transaminase (Agt) from Saccharomyces cerevisiae [151]. Glycine is subsequently converted to serine by adding methylene- $\mathrm{H}_{4} \mathrm{~F}$, as in the natural serine cycle. Serine is finally deaminated to pyruvate through serine dehydratase (Sdh) from Cupriavidus necator, and PEP is regenerated by the action of endogenous phosphoenolpyruvate synthetase (Pps), thus avoiding the intermediate hydroxypyruvate (Figure 4) [151]. Formaldehyde assimilation via the modified serine cycle was demonstrated through coassimilation of formate or methanol with xylose by isotope labelling experiments [151].

Another variant of the serine cycle is the synthetic serine-threonine cycle (Table 3, Figure 4) [152]. The idea behind the creation of this pathway is to fit the endogenous metabolism of a model host, in this case E. coli, in order to avoid introducing non-natural and conflicting fluxes [152]. Moreover, this pathway seeks to avoid interference with central metabolic fluxes, given that the natural serine cycle shares reactions with PPP, glycolysis, and the TCA cycle $[110,152]$. The E. coli genome encodes all the enzymes of the novel pathway except for the formate-tetrahydrofolate ligase (Ftl), which is required to be heterologously expressed in order to assimilate the C1 compound formate [152]. Similar to the modified serine pathway, this adaptation also circumvents the formation of hydroxypyruvate as intermediate; however, serine is here converted to pyruvate by the action of serine deaminase SdaA (Figure 4) [152]. An additional variation is the conversion of oxaloacetate to aspartate catalyzed by aspartate aminotransferase (AspC) for further recycling of glycine via the threonine biosynthesis and cleavage system, which was achieved by overexpression of threonine-cleaving enzymes threonine dehydrogenase $(\mathrm{Tdh})$ and 2-amino-3-ketobutyrate CoA ligase (Kbl). This strategy resulted in high compensatory flux towards threonine biosynthesis, which fueled subsequent glycine production (Figure 4) [152]. By avoiding the conversion of oxaloacetate to malate and further to glyoxylate, the need to heterologously express genes coding for the uncommon enzymes of the natural serine cycle Mtk and Mcl was avoided, succeeding in the goal to adapt the cycle to the endogenous metabolism of E. coli [152]. By simultaneous activity of the different pathway sections of the serine-threonine cycle, Yishai et al. successfully achieved formate-dependent growth in E. coli strains auxotrophic to the C1-building blocks and serine [152].

Several of the shortcomings displayed by the natural serine cycle, some of them already mentioned, also inspired the design of the homoserine cycle (Table 3, Figure 4) [110]. Three key aspects were tackled in implementing this cycle into the E. coli host [110]. Firstly, it was aimed to avoid the competition of flux between the pathway reactions and those of the central metabolism, a shared goal with the serine-threonine cycle [110]. Secondly, the focus was put on reducing the thermodynamic disadvantages of the natural serine cycle [110]. The third aspect was to avoid $\mathrm{CO}_{2}$ fixation that follows formaldehyde assimilation since ATP needs to be invested in order to energize carboxylation, and two reduction steps are required to fix $\mathrm{CO}_{2}$ in order to bring the carbon to the average oxidation state of carbon in biomass [110]. In order to undertake those issues, He et al. considered characterized promiscuous activities of E. coli native enzymes to catalyze all non-natural reactions of the homoserine cycle instead of relying on completely novel reactions [110]. Based on those prerequisites, the homoserine cycle progresses as follows: glycine is directly condensed with formaldehyde to generate serine, catalyzed by the serine aldolase (Sal) reaction, which is promiscuously catalyzed by the E. coli threonine aldolase (LtaE) (Figure 4) [110]. This reaction successfully bypasses the long, multicofactor-dependent and ATP-inefficient 
route for formaldehyde condensation to methylene- $\mathrm{H}_{4} \mathrm{~F}$ [110]. After serine is directly converted to pyruvate as described in the serine-threonine cycle, pyruvate is condensed with formaldehyde to generate the non-native metabolite 4-hydroxy-2-oxobutanoate (HOB) by HOB aldolase (Hal) reaction, which is promiscuously catalyzed by E. coli 2-keto-3deoxy-L-rhamnonate aldolase (RhmA) (Figure 4) [110]. HOB is subsequently aminated to homoserine by $\mathrm{HOB}$ aminotransferase (Hat), a reaction supported by various endogenous aminotransferases [110]. These reactions effectively replace carboxylation with a formaldehyde assimilation reaction that provides an alternative way to generate a $\mathrm{C} 4$ intermediate, with formaldehyde being already at the average oxidation state of cellular carbon [110]. Homoserine is later metabolized by homoserine kinase (Hsk) and threonine synthase (Ts) to produce threonine [110]. Threonine is then cleaved by LtaE that also catalyzes the Sal reaction, to ultimately regenerate glycine and produce acetaldehyde, which will be further oxidized to acetyl-CoA (Figure 4) [110]. The feasibility of the homoserine cycle was demonstrated in vivo in several E. coli auxotrophic strains whose growth was coupled to the activity of separate homoserine cycle segments [110]. Methanol-dependent conversion of homoserine to glycine and serine and derivation of homoserine and its downstream products from pyruvate and methanol were confirmed individually through ${ }^{13} \mathrm{C}$-labeling experiments [110]. Although these results only confirm the functionality of the homoserine cycle in two separate segments, they are promising first steps towards the establishment of methylotrophic growth via the complete homoserine cycle [110].

\subsection{Novel Pathways for Assimilation of Formaldehyde}

In recent times, the development of novel assimilation pathways has received increasing interest, with some of these promising alternative pathways described here. The dihydroxyacetone (DHA) synthase (DAS) pathway is a cyclic formaldehyde assimilation pathway designed using in silico modelling [101]. It was built starting with the tool FindPath to identify the most efficient pathway for E. coli to consume methanol [101,153]. This resulted in two equally promising hits: a RuMP-based pathway and a hybrid metabolic pathway involving bacterial Mdh from Acinetobacter gerneri and yeast DAS from Pichia angusta, the latter referred to as the aforementioned DAS pathway (Table 4, Figure 5) [101]. DAS is a transketolase that catalyzes the condensation of formaldehyde with Xu5P yielding GAP and DHA in the XuMP pathway present in methylotrophic yeasts [101]. A library of 266 variants containing different combinations of Mdh and DAS homologues was built and screened using high-throughput ${ }^{13} \mathrm{C}$-labeling experiments [101]. Transcriptional analysis of the expression of genes involved in methanol metabolism indicated that DHA generated from the DAS reaction is subsequently converted to DHAP and Xu5P is regenerated through the activity of F6P aldolase (Fsa), which catalyzes the generation of F6P from GAP and DHA, and TktA which catalyzes the transfer of the C2 keto group from F6P to GAP to form Xu5P and E4P (Figure 5). With the novel pathway, incorporation of $22 \%$ methanol carbon was observed in PEP using xylose as cosubstrate, which is similar to values previously reported under comparable cultivation conditions in synthetic methylotrophy attempts in E. coli strains expressing the RuMP cycle [101]. Further improvement of the pathway through omics and modelling approaches led to a final optimized strain with a maximum ${ }^{13} \mathrm{C}$-enrichment of 37\% in glycerol 3-phosphate [101]. 

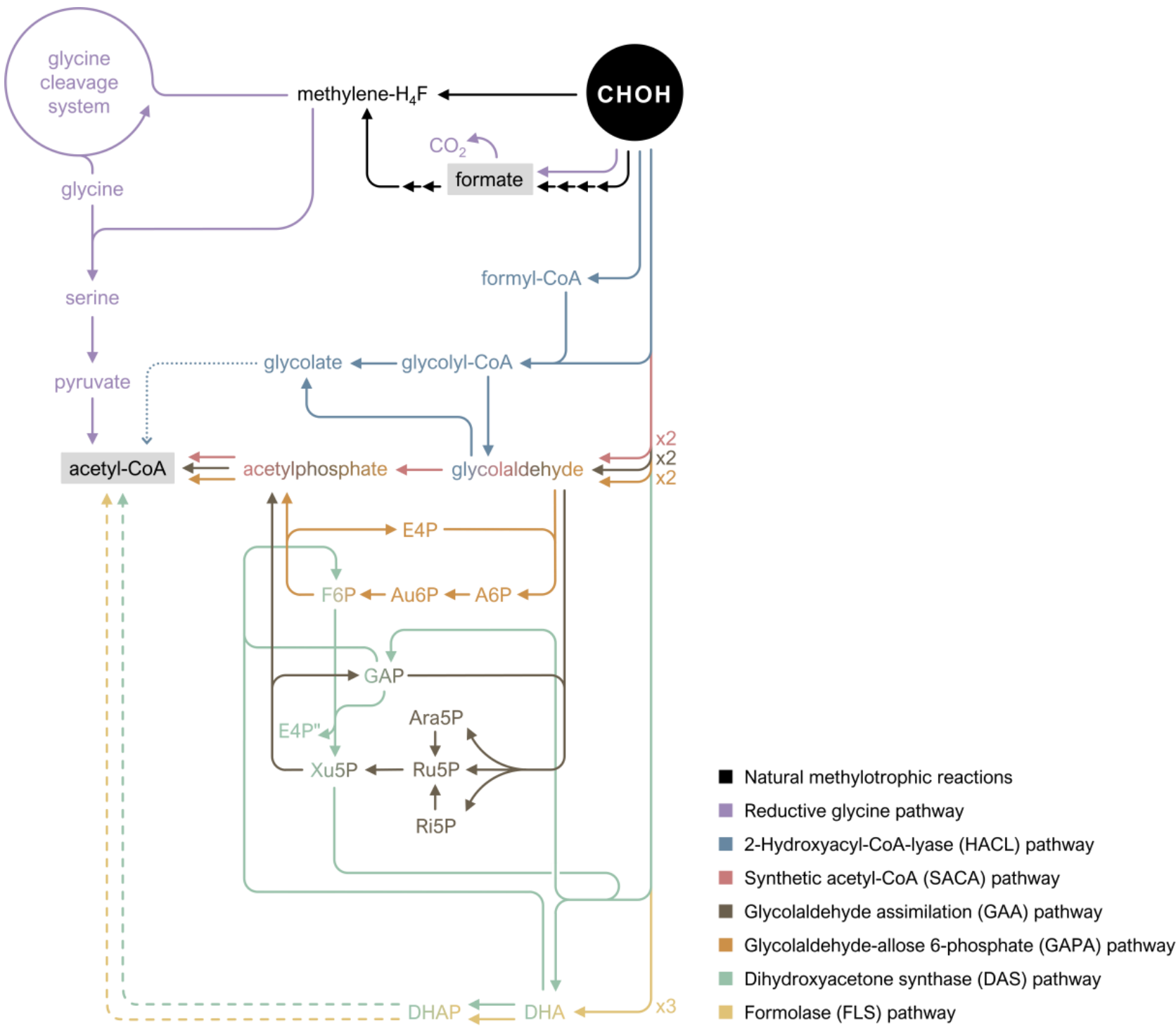

Figure 5. Novel methylotrophic pathways based on natural and synthetic C1-fixing reactions. Schematic overview of the reductive glycine pathway (violet), the HACL pathway (blue), the SACA pathway (red), the GAA pathway (brown), the GAPA pathway (orange), the DAS pathway (green), and the FLS pathway (yellow). Dashed arrows represent multiple reactions. Dotted arrows represent the proposed link to central carbon metabolism. Metabolites: $\mathrm{CHOH}=$ formaldehyde; $\mathrm{E} 4 \mathrm{P}=$ erythrose 4-phosphate; F6P = fructose 6-phosphate; Au6P = D-allulose 6-phosphate; A6P = 2R,3R-stereo allose 6-phosphate; GAP = glyceraldehyde 3-phosphate; $\mathrm{Xu} 5 \mathrm{P}=$ xylulose 5-phosphate; Ara5P = arabinose 5-phosphate; Ru5P = ribulose 5-phosphate; Ri5P = ribose 5-phosphate; DHA = dihydroxyacetone; $\mathrm{DHAP}=$ dihydroxyacetone phosphate; $\mathrm{H}_{4} \mathrm{~F}$ = tetrahydrofolate. Relevant metabolites are highlighted in a grey box. Some metabolites were duplicated for clearer visualization and are indicated with quotation marks (").

The naturally occurring formaldehyde assimilation pathways and their modifications presented so far are cyclic, require regeneration of formaldehyde acceptors and overlap with central carbon metabolism, making their implementation into nonmethylotrophs challenging in terms of flux balancing between the transferred pathway and its convergence with core metabolism [154]. A different strategy to reshape natural pathways is designing novel, linear pathways based on existing C1-fixing reactions [155]. One example is the reductive glycine pathway, a simple, linear route with small overlap with central metabolism, minimizing requirements in regulatory optimization (Table 4, Figure 5) [156]. 
The pathway can be divided into four modules: (i) The $\mathrm{C} 1$ module, which consists of $\mathrm{Ftl}$, methenyl- $\mathrm{H}_{4} \mathrm{~F}$ cyclohydrolase $(\mathrm{Fch})$ and methylene- $\mathrm{H}_{4} \mathrm{~F}$ dehydrogenase (MdtA) from M. extorquens AM1, converting formate into methylene- $\mathrm{H}_{4} \mathrm{~F}$; (ii) The $\mathrm{C} 2$ module, which consists of endogenous E. coli host enzymes of the glycine cleavage system (GcvT, GcvH and GcvP), condensing methylene- $\mathrm{H}_{4} \mathrm{~F}$ with $\mathrm{CO}_{2}$ and ammonia to yield glycine; (iii) The C3 module which consists of native Shmt and serine deaminase, condensing glycine with another methylene- $\mathrm{H}_{4} \mathrm{~F}$ to generate serine and ultimately pyruvate; (iv) An energy module, which consists of formate dehydrogenase (Fdh) from Pseudomonas sp. strain 101, generating reducing power and energy from formate and thus making this $\mathrm{C} 1$ feedstock serve as both carbon and energy source (Figure 5) [156]. After several optimization steps that involve establishing the separate modules for subsequent integration for their combined activity and short-term evolution, Kim et al. successfully generated an E. coli strain capable of growing solely on formate and $\mathrm{CO}_{2}$ [156]. With the introduction of an additional methanol module by heterologous expression of the G. stearothermophilus gene encoding Mdh, growth on a mixture of methanol and $\mathrm{CO}_{2}$ could also be achieved, increasing the methylotrophic scope of this pathway [156]. The amino acid labelling patterns detected via ${ }^{13} \mathrm{C}$-labeling experiments confirmed that growth on both conditions indeed takes place via the introduced synthetic route [156].

Table 4. List of novel methylotrophic pathways.

\begin{tabular}{|c|c|c|c|}
\hline Pathway ${ }^{1}$ & Characteristic & Host Organism & Reference \\
\hline Reductive glycine pathway & $\begin{array}{l}\text { Linear route that can be divided } \\
\text { into four modules; small overlaps } \\
\text { with the central metabolism } \\
\text { minimizes requirements in } \\
\text { regulatory optimization }\end{array}$ & E. coli & [156] \\
\hline HACL pathway & $\begin{array}{l}\text { Synthetic pathway based on the } \\
\text { ligation of formaldehyde with } \\
\text { formyl-CoA; whole-cell biocatalysis } \\
\text { of glycolate }\end{array}$ & E. coli & [114] \\
\hline SACA pathway & $\begin{array}{l}\text { Synthetic linear pathway based on } \\
\text { condensation of two formaldehyde } \\
\text { molecules using designed Gals }\end{array}$ & E. coli & [159] \\
\hline $\begin{array}{c}\text { FLS } \\
\text { pathway }\end{array}$ & $\begin{array}{l}\text { Synthetic pathway in which the } \\
\text { computationally designed enzyme } \\
\text { FLS catalyzes the carboligation of } \\
\text { three formaldehyde molecules }\end{array}$ & E. coli & {$[113,157]$} \\
\hline GAA pathway & $\begin{array}{l}\text { Synthetic pathway based on } \\
\text { computationally-predicted } \\
\text { ATP-independent and } \\
\text { carbon-conserving reactions; starts } \\
\text { with condensation of two } \\
\text { formaldehyde molecules using Gals }\end{array}$ & Has not been applied in vivo yet & [160] \\
\hline DAS pathway & $\begin{array}{c}\text { Synthetic pathway based on } \\
\text { bacterial Mdh and yeast DAS } \\
\text { identified via in silico modelling }\end{array}$ & E. coli & [101] \\
\hline GAPA pathway & $\begin{array}{l}\text { Synthetic pathway based on the } \\
\text { introduction of non-natural } \\
\text { aldolase reactions; starts with } \\
\text { condensation of two formaldehyde } \\
\text { molecules using Gals }\end{array}$ & Has not been applied in vivo yet & [158] \\
\hline
\end{tabular}

${ }^{1}$ Synthetic pathways mentioned in this review, their characteristics and host organisms.

The development of synthetic alternative formaldehyde assimilation pathways based on non-natural C1-fixing reactions has also received considerable interest [36]. These 
pathways rely in most cases on enzymes that condense formaldehyde with an additional substrate to generate a relevant metabolite for cell growth [36]. One of the main advantages of these pathways is the lack of need to regenerate the initial formaldehyde acceptors Ru5P or glycine [36]. The so-called formolase (FLS) pathway was the first of such pathways to be developed, where an FLS enzyme was engineered via computational protein design to catalyze the carboligation of three formaldehyde molecules into one DHA molecule, which can enter lower glycolysis via DHAP (Table 4, Figure 5) [157]. In a later study, after several rounds of ALE, ${ }^{13} \mathrm{C}$-labeling experiments showed that the FLS pathway could successfully support methanol-based growth in E. coli with the combined activity of Mdh from B. methanolicus PB1 and a small amount of yeast extract [113]. This route offers a linear and straightforward way to generate a metabolite that can directly enter central carbon metabolism. However, the catalytic efficiency of FLS is way below that of the average enzyme and still exhibits one-third carbon loss during acetyl-CoA synthesis [36,158].

Another pathway based on formaldehyde condensation is the synthetic acetyl-CoA (SACA) pathway, where a glycolaldehyde synthase (Gals) catalyzes the condensation of two formaldehyde molecules to glycolaldehyde, which is subsequently converted by an Actinobacteria-derived Pkt with acetylphosphate synthase activity to acetylphosphate (Table 4, Figure 5). Finally, acetyl-CoA is generated via the action of a Pta, which represents the shortest of the pathways presented in this review [159]. The chosen Gals was designed and engineered to improve its catalytic activity more than 70-fold [159]. The SACA pathway feasibility was first demonstrated in vitro by ${ }^{13} \mathrm{C}$-labeled metabolites, which achieved a carbon yield of $\sim 50 \%$, and later verified in vivo in E. coli using glycolaldehyde, formaldehyde, or methanol as supplementary carbon sources [159]. Even though the SACA pathway is thermodynamically favourable theoretically, surpassing both the MCC and FLS pathway, both Gals and Pkt displayed low substrate affinities in vivo [159]. Moreover, acetylphosphate synthase activity by Pkt was inhibited by formaldehyde [159]. This was partially circumvented through the introduction of Mdh to allow for methanol utilization to provide a slow supply of formaldehyde [159]. By this concomitant use of G. stearothermophilus $\mathrm{Mdh}$, the addition of ${ }^{13} \mathrm{C}$-methanol resulted in $17 \%$ average carbon labelling in PEP, which validated formaldehyde assimilation via the synthetic pathway, albeit contributing only to 3\% biomass from methanol [159].

Similarly, the glycolaldehyde assimilation (GAA) in vitro pathway relies on the condensation of two formaldehyde molecules (Table 4, Figure 5). When designing this pathway, Yang et al. predicted 59 ATP-independent and carbon-conserving formaldehyde assimilation pathways using a combinatorial algorithm, the so-called comb-flux balance analysis [160]. The applied algorithm computed multiple optimal pathways in metabolic networks using known reactions from the MetaCyc database and predicted aldolase reactions from the ATLAS database [160]. Interestingly, all 59 pathways contained at least one reaction catalyzed by $\mathrm{Pkt}$, which was previously described when defining the MCC (Section 3.1) and played an important role in the energy-free carbon-conserving conversion of C1 to C2 products [160]. Further evaluation of the pathways led to the selection of those without kinetic traps and the search for enzymes to catalyze the computationally predicted reactions, which ultimately allowed the construction of the GAA pathway [160]. In this in vitro multienzyme system, two formaldehyde molecules are first condensed to glycolaldehyde by an engineered Gals as in the SACA pathway (Figure 5) [159-161]. Glycolaldehyde is then condensed with GAP by an engineered Ta (TalB ${ }^{\mathrm{F} 178 \mathrm{Y}}$ ) from E. coli to form three pentose 5-phosphate compounds: Ri5P, Ru5P and arabinose 5-phosphate (Ara5P), Ara5P being the main product $[160,162]$. By adding Ara5P isomerase (KdsD), Ara5P can be redirected to Ru5P, and further activity of Rpe converts Ru5P to Xu5P [160]. Finally, Pkt cleaves $\mathrm{Xu5P}$ to generate the acetyl-CoA precursor acetylphosphate and regenerate GAP (Figure 5) [160]. After pathway optimization, the synthetic GAA pathway reached 88\% product carbon yield [160].

The in vitro glycolaldehyde-allose 6-phosphate (GAPA) pathway was developed by the same group that previously constructed the GAA pathway (Table 4, Figure 5) [158]. 
For this approach, they reused their comb-flux balance analysis but introduced artificially proposed 28 non-natural aldolase reactions not present in the ATLAS database to the known reaction set [158]. This led to the prediction of eight new pathways and two novel aldolase reactions, which ultimately resulted in the construction of the GAPA pathway [158]. This pathway starts with the condensation of two formaldehyde molecules by Gals to yield glycolaldehyde as in both the SACA and GAA pathways (Figure 5) [158]. Glycolaldehyde is subsequently condensed with $\mathrm{E} 4 \mathrm{P}$ and converted to $2 R, 3 R$-stereo allose 6-phosphate (A6P) by the novel aldolase reaction catalyzed by DeoC [158]. A6P is then isomerized to D-allulose 6-phosphate (Au6P) by allose 6-phosphate isomerase/ribose 5-phosphate isomerase B (RpiB) and subsequently epimerized to F6P by D-allulose-6-phosphate 3epimerase (AlsE). F6P is finally hydrolyzed by Pkt similarly to MCC and GAA pathway to produce acetylphosphate and regenerate E4P (Figure 5) [158]. Upon adding all the enzymes to the reaction system, the concentration of acetylphosphate corresponded to a carbon yield of $94 \%$ for glycolaldehyde in the GAPA pathway [158].

Another potential strategy for formaldehyde assimilation involves the activity of 2-hydroxyacyl-CoA-lyase (HACL), an enzyme known to be involved in mammalian $\alpha$ oxidation, that can act reversibly and catalyze the ligation of carbonyl-containing molecules with formyl-CoA to produce C1-elongated 2-hydroxyacyl-CoAs [114]. A prokaryotic variant of HACL from Rhodospirillales bacterium with this newfound activity was discovered and functionally expressed in E. coli for the first time [114]. The expression of prokaryotic HACL in E. coli allowed for ligation of formaldehyde with formyl-CoA to generate the C2 compound glycolyl-CoA via C1 biocatalysis [114]. In order to generate the HACL cosubstrate formyl-CoA, an acyl-CoA reductase from Listeria monocytogenes was used for in situ formyl-CoA production from formaldehyde [114]. This engineered E. coli whole-cell biocatalyst ultimately allowed for the production of glycolate and 2-hydroxyisobutyrate from formaldehyde and formaldehyde and acetone, respectively, achieving up to $84 \%$ carbon yield (Table 4, Figure 5) [114,158]. Notably, the HACL pathway allowed for glycolate production using formaldehyde as the sole substrate [114]. Although no cell growth was derived from formaldehyde in the implemented HACL-based biocatalysis, the results presented in this work serve as a valuable proof-of-concept for its further application in synthetic methylotrophy, as the produced glycolate does not only represent a valuable endproduct but could also serve as a substrate for subsequent assimilation into central carbon metabolism [114]. Moreover, given that glycolaldehyde is an intermediate, an alternative would be to couple the HACL pathway with the SACA pathway reactions catalyzed by Pkt and Pta, which would yield acetyl-CoA in only two more steps (Figure 5).

While all the aforementioned pathways contribute to promising alternatives theoretically and demonstrate that computational design and enzyme engineering are significant assets for developing competitive synthetic methylotrophy pathways, the poor kinetic properties observed in vivo or lack of proof-of-concept in bacterial cells are still a limitation in their applicability today.

\section{The Understanding of Formaldehyde Metabolism Regulation as a Support to Push Synthetic Methylotrophy}

Due to the high toxicity of formaldehyde, its metabolism requires sensitive and finetuned regulation systems. Particularly, in methylotrophic microorganisms, formaldehyde metabolism is often regulated through multilevel cascade systems. For example, in the methylotrophic $P$. denitrificans, the formaldehyde metabolism is controlled by a two-component system consisting of FlhR and FlhS (Table 5) [163,164]. The FlhRS system regulates the expression of enzymes that are either involved in production of formaldehyde (Mdh and methylamine dehydrogenase (Madh) or its consumption (GD-Faldh, Fgh) [40,163-165]. The FlhRS system is activated, and its expression is induced by the presence of formaldehyde and by the depletion of heterotrophic substrates $[163,164]$. This regulatory system consists of a signal (FlhS) and a response regulator (FlhR) that binds to DNA [164]. FlhS is a histidine kinase that, when activated through the binding of effec- 
tor molecules, catalyzes the phosphorylation of FlhR [164]. As soon as FlhR is activated through phosphorylation, it binds to target promoters of C1 metabolism gene clusters, resulting in the expression of genes encoding Fgh and GD-Faldh [163,164]. The upregulation of the expression of these genes takes place during growth on methanol, while they are constitutively expressed at basal levels also during heterotrophic cultivation [164]. Consequently, GD-Faldh and Fgh are synthesized, and thus formaldehyde is converted to $\mathrm{CO}_{2}$, which prevents the accumulation of its toxic concentrations [164]. This means that initially, only the formaldehyde-consuming enzymes are synthesized. When formaldehyde concentration increases, the activated FlhR binds to promoters of the operons mxa (encoding Mdh) and mau (encoding Madh), which, however, does not directly lead to their activation [163,164]. The expression of $m x a$ and mau is induced by binding the additional regulator MxaX or MauR for expression of mxa and mau, respectively [164]. The regulatory systems derived from $P$. denitrificans were used to create synthetic regulators that can potentially be applied for dynamic gene expression control in synthetic methylotrophs. For example, the sensoring kinase domains of MxaY or FlhS derived from P. denitrificans were fused with the cytoplasmic catalytic domain of the osmosensor histidine kinase EnvZ from $E$. coli in order to create a chimeric sensor histidine kinase that responds to the presence of methanol in the environment $[163,166]$. A similar approach was used to create a methanol sensor by combining the sensing domain of MxcQ derived from M. organophilum XX or M. extorquens AM1, or M. extorquens AM1-derived MxbD with the transmitter domain of EnvZ from E. coli $[167,168]$.

Besides methanol-sensing regulators, M. extorquens AM1 possesses a unique, recently discovered formaldehyde sensor enhanced formaldehyde growth protein A (EfgA), which contributes to formaldehyde detoxification not through enzymatic oxidation but relying on binding with this compound [169]. In response to the transient increase of intracellular formaldehyde concentration, EfgA leads to a rapid halt of protein translation and arrest of cell growth which could limit formaldehyde-induced protein damage [169]. Moreover, the changes in the translation are potentially linked to the global transcriptional response to formaldehyde stress mediated by EfgA [170]. Transcriptional response targets biosynthesis of free formaldehyde, contributes to increased formaldehyde consumption by Fae, mitigates proteotoxicity and genotoxicity, and is reversed when formaldehyde concentration decreases [170]. Expression of $e f g A$ is regulated by TtmR (Table 5), a formaldehyde-responsive MarR family transcription factor, and both EfgA and TtmR are required for the optimal transition from multicarbon to $\mathrm{C} 1$ growth [171]. It was shown that heterologous expression of $M$. extorquens AM1-derived efg $A$ in $E$. coli increases its formaldehyde resistance, indicating the potential application of EfgA in strategies to increase formaldehyde tolerance during the engineering of synthetic methylotrophy [169].

Methylotrophic growth activates formaldehyde assimilation and dissimilation pathways which should actively control intracellular formaldehyde concentrations. In the facultative methylotroph $B$. methanolicus MGA3 some of the genes involved in the RuMP formaldehyde assimilation cycle are upregulated during growth on methanol versus heterotrophic conditions. However, details of the expression regulation are not elucidated, and the regulator is not yet known. B. methanolicus MGA3 cells grown on methanol are more sensitive to formaldehyde than MGA3 cells grown on a nonmethylotrophic substrate [172]. The increased formaldehyde sensitivity during methylotrophic growth might be caused by the already high formaldehyde concentration in the cells grown in methanol and thus the saturation of formaldehyde assimilation and dissimilation pathways in this bacterium. For that reason, supplementation with external formaldehyde can lead to increased formaldehyde toxicity [172]. One of the regulators present in B. methanolicus MGA3 is HxlR, which controls the expression of chromosomal genes $h p s$ and $p h i$, upregulated by formaldehyde (Table 5) [133]. It was shown that the introduction of additional copies of hps and phi through plasmid-based overexpression increases the tolerance of $B$. methanolicus MGA3 cells to high methanol concentrations confirming the central role of that operon in $\mathrm{C} 1$ metabolism [133]. 
The structure of the formaldehyde-responsive transcription factor HxlR was also studied in the nonmethylotroph B. subtilis (Table 5). Similarly to TtmR, HxlR belongs to the MarR family of transcription factors, and it controls the expression of $h x l A B$ in $B$. subtilis [86,173]. HxlR recognizes formaldehyde through a protein intra-helical cysteine-lysine cross-linking reaction at its N-terminal $\alpha 1$ helix, which in turn leads to a conformational change and transcriptional activation [173]. The resulting intrahelical methylene bridge is a protein modification with a conformational change that allosterically induces transcriptional activation of HxIR [173]. Another regulator responsible for controlling the expression of genes involved in formaldehyde metabolism in B. subtills is AdhR (Table 5). AdhR regulates the expression of the $\mathrm{BSH}$-dependent formaldehyde dissimilation pathway in B. subtilis and belongs to an NmlR clade within the family of MerR repressor-activators [19]. MerR regulators are sensitive to a wide range of molecules such as soft transition metal ions, the superoxide anion, and drug-like compounds, whereas the members of the NmlR clade respond to oxidative and carbonyl stressors [81,174-176]. Similar to other formaldehyde sensors, a cysteine residue is conserved within the NmlR clade; for example, Cys52 is conserved in AdhR from B. subtilis [81]. Replacement of this residue with alanine leads to the creation of a strain where $a d h A(a d h C)$ is not transcribed in a formaldehyde rich environment [81].

Table 5. List of regulators involved in processes controlling formaldehyde metabolism in bacteria.

\begin{tabular}{cccc}
\hline Regulator ${ }^{1}$ & Regulated Processes & Example Organism & Reference \\
\hline FlhRS & $\begin{array}{c}\text { Production of formaldehyde (Mdh } \\
\text { and Madh) or its consumption } \\
\text { (GD-Faldh, Fgh) }\end{array}$ & P. denitrificans & {$[40,163-165]$} \\
HxlR & $\begin{array}{c}\text { Hps-Phi in RuMP cycle (assimilatory } \\
\text { or dissimilatory variant) }\end{array}$ & B. methanolicus MGA3, B. subtilis & M. extorquens AM1 \\
\hline TtmR & $\begin{array}{c}\text { EfgA-mediated formaldehyde } \\
\text { stress response }\end{array}$ & B. subtilis \\
\hline AdhR & $\begin{array}{c}\text { BSH-dependent formaldehyde } \\
\text { dissimilation pathway }\end{array}$ & E. coli \\
\hline FrmR & $\begin{array}{c}\text { GSH-dependent formaldehyde } \\
\text { dissimilation pathway composed of } \\
\text { GD-Faldh and Fgh }\end{array}$ & [171] \\
\hline RamAB, GlxR & $\begin{array}{c}\text { Ald-mediated formaldehyde } \\
\text { dissimilation process }\end{array}$ & C. glutamicum \\
\hline
\end{tabular}

Regulation of expression of the formaldehyde metabolic pathway in C. glutamicum is not well characterized. The expression pattern of the gene encoding NAD-linked MSHdependent formaldehyde dehydrogenase is not known, and neither is its regulation [91]. Expression of ald encoding acetaldehyde dehydrogenase that catalyzes the oxidation of formaldehyde depends on the carbon source used for the cultivation of C. glutamicum. The activity of Ald increases about 10-fold when ethanol is a carbon source as compared to growth with glucose or mixtures of glucose with ethanol [91,177]. This process is regulated by RamA and RamB and putatively by GlxR (Table 5) [91,177]. Thus, due to differential gene expression, the importance of Ald and FadH might vary depending on the physiological conditions [91]. Methanol catabolism is subject to carbon catabolite repression in the presence of glucose and is dependent on the transcriptional regulator RamA, which was previously shown to be essential for the expression of $a d h A$ and ald [90].

A well-characterized system for the control of formaldehyde metabolism is present in heterotrophic E. coli. In this bacterium, yeiG encoding Fgh is constitutively expressed, while the expression of Fgh-encoding frmB, which belongs to the frmR $A B$ operon, increases by 20- 
to 100-fold over basal levels in the presence of formaldehyde in the environment [98,99]. FrmR is a member of the CsoR/RcnR family of metal ion-sensing transcriptional repressors, which is responsible for controlling the frmR $A B$ operon (Table 5) [178-180]. In the absence of formaldehyde, FrmR binds to the promoter of the frmRAB operon $\left(\mathrm{P}_{f r m}\right)$, while in its presence FrmR changes its conformation, which leads to the dissociation of the $\mathrm{P}_{f r m}$-FrmR complex [180]. The change of protein conformation is caused by the formation of methylene bridges that link adjacent proline (Pro2) and cysteine (Cys35) residues in the FrmR tetramer [180]. The allosteric mechanism of FrmR is triggered directly by formaldehyde in vitro [180]. Sensitivity to formaldehyde requires a cysteine (Cys35 in FrmR) conserved in all DUF156 proteins [181].

As highlighted by the limited success in a full transfer of methylotrophy, and the importance of fine-tuning the $\mathrm{C} 1$ metabolic landscape, an important approach to synthetic methylotrophy is the implementation of dynamic formaldehyde regulation mechanisms. The formaldehyde-inducible promoter $P_{\text {frm }}$ was engineered to obtain variants differing in their basal and induced expression levels [182]. A variant of the formaldehyde-responsive promoter characterized with higher basal and induced expression levels compared with $\mathrm{P}_{f r m}$ was used for the control of $m d h$ and $h x l A B$ in a $\triangle$ frmA $\Delta p g i$ E. coli genetic background, which led to improved biomass yield in comparison to the strain where the native E. coli $\mathrm{P}_{f r m}$ was used [182]. Furthermore, using the formaldehyde-inducible promoter $\mathrm{P}_{f r m}$ to drive direct regulation of rpe and tkt genes involved in the regeneration of Ru5P led to significantly improved methanol assimilation into intracellular metabolites in E. coli [118]. Global gene regulation is an additional factor that should be considered in establishing synthetic methylotrophy. The use of the non-native substrate methanol for growth likely triggers the response characteristic for nutrient-limiting conditions in E. coli [105]. Such response is characterized by diverting resources away from active growth and division in favour of maintenance and stress resistance leading to inhibition of RNA synthesis [105]. This leads to decreased translation and conservation of amino acids concurrent with the upregulation of many amino acid biosynthetic genes [105]. It was shown that the activation of stringent response via overproduction of guanosine tetraphosphate (ppGpp) or enzymes involved in its biosynthesis (RNA polymerase-binding transcription factor DksA and the stress response sigma factor RpoS) enhances methanol utilization in synthetic methylotroph E. coli by enabling the biosynthesis of several limiting amino acids using carbon derived from methanol in comparison to the control strain where such amino acids cannot be synthesized [105].

Altogether, a comprehensive understanding of formaldehyde metabolism and its regulation in native methylotrophs is an invaluable asset in designing strategies for its introduction into nonmethylotrophic species. The hitherto research showcases the importance of finding a balance between oxidation of $\mathrm{C} 1$ substrates to formaldehyde, endogenous formaldehyde dissimilation, and introduction of synthetic formaldehyde assimilation pathways in order to properly regulate carbon flux towards assimilation and maintain formaldehyde below toxic levels. As exemplified in this review, formaldehyde dissimilation pathways and their regulation seem to be relatively conserved among different bacterial species regardless of their trophic lifestyle, which means that native pathways on nonmethylotrophs can potentially be used in the engineering efforts for synthetic methylotrophy.

\section{Concluding Remarks and Future Perspectives}

Despite the simplicity of the concept, the introduction of synthetic methylotrophy into nonmethylotrophic bacteria has turned out to be a challenging task due to numerous unpredicted constraints. The study and in-depth understanding of native formaldehyde metabolism of methylotrophic strains can offer valuable input to solve those impediments. As discussed in this review, the major factors that affect formaldehyde assimilation are the rate of formaldehyde formation from its $\mathrm{C} 1$ precursors, the balance of carbon flux between formaldehyde assimilation and dissimilation, carbon and energy balance yielded by various 
pathways, and regulation of those processes. Here, the overview of such considerations is provided, serving as a roadmap for future attempts to establish synthetic methylotrophy. A strategy that arises as a seemingly promising alternative is the creation of novel, optimized synthetic pathways designed to circumvent many of the obstacles presented here through the use of optimized enzymes and metabolic shunts.

Funding: V.J.K. was funded by the Department of Biotechnology and Food Science at the Norwegian University of Science and Technology. M.I. was funded by the Centre for Digital Life Norway. M.G.L. was funded by NTNU Biotechnology. T.B. and L.F.B. were funded by The Research Council of Norway within ERA CoBioTech, project number 327216.

Institutional Review Board Statement: Not applicable.

Informed Consent Statement: Not applicable.

Data Availability Statement: Not applicable.

Acknowledgments: We thank Marco Giampà for valuable discussion about chemistry of formaldehyde toxicity.

Conflicts of Interest: The authors declare no conflict of interest.

\section{List of Abbreviations}

$\begin{array}{ll}\text { Metabolites } & \\ \text { 6PG } & \text { 6-phosphogluconate } \\ \text { 6PGL } & \text { 6-phospho-glucono-1,5-lactone } \\ \text { A6P } & \text { 2R,3R-stereo allose 6-phosphate } \\ \text { Ara5P } & \text { arabinose 5-phosphate } \\ \text { Au6P } & \text { D-allulose 6-phosphate } \\ \text { BSH } & \text { bacillithiol } \\ \text { CHOH } & \text { formaldehyde } \\ \text { DHA } & \text { dihydroxyacetone } \\ \text { DHAP } & \text { dihydroxyacetone phosphate } \\ \text { E4P } & \text { erythrose 4-phosphate } \\ \text { F6P } & \text { fructose 6-phosphate } \\ \text { FBP } & \text { fructose 1,6-bisphosphate } \\ \text { G6P } & \text { glucose 6-phosphate } \\ \text { GAP } & \text { glyceraldehyde 3-phosphate } \\ \text { GAPA } & \text { glycolaldehyde-allose 6-phosphate } \\ \text { GSH } & \text { glutathione } \\ \text { H }{ }_{4} F & \text { tetrahydrofolate } \\ \text { H } 4 \text { MPT } & \text { tetrahydromethanopterin } \\ \text { HOB } & \text { 4-hydroxy-2-oxobutanoate } \\ \text { Hu6P } & \text { hexulose 6-phosphate } \\ \text { Ln } & \text { lanthanide } \\ \text { MSH } & \text { mycothiol } \\ \text { PEP } & \text { phosphoenolpyruvate } \\ \text { PQQ } & \text { pyrroloquinoline quinone } \\ \text { Ri5P } & \text { ribose 5-phosphate } \\ \text { RuBP } & \text { ribulose bisphosphate } \\ \text { Ru5P } & \text { ribulose 5-phosphate } \\ \text { S7P } & \text { sedoheptulose 7-phosphate } \\ \text { SBP } & \text { sedoheptulose 1,7-bisphosphate } \\ \text { TCA } & \text { tricarboxylic acid } \\ \text { Xu5P } & \text { xylulose 5-phosphate } \\ \text { XuMP } & \text { xylulose monophosphate } \\ & \end{array}$


Proteins

Agt

Ald

AlsE

AspC

CyaA

DAS

DL-Faldh

EfgA

Fae

Faldh

FBPa

Fch

Fdh

Fgh

FlhR

FlhS

FLS

Fsa

Ftl

Gals

GD-Faldh

Gfa

HACL

Hal

Hat

$\mathrm{HOB}$

$\mathrm{Hpr}$

Hps

Hsk

Icd

$\mathrm{Kbl}$

KdsD

LtaE

Madh

Maldh

$\mathrm{Mcl}$

Mdh

MdtA

Mtk

Phi

Pkt

Pps

Pta

RhmA

Rpe

Rpi

RpiB

Sal

SASP

SBPase

Sdh

Shmt

Ta

Tdh

Tkt

Ts alanine-glyoxylate transaminase

acetaldehyde dehydrogenase

D-allulose-6-phosphate 3-epimerase

aspartate aminotransferase

adenylate cyclase

dihydroxyacetone synthase

dye-linked dehydrogenase

enhanced formaldehyde growth protein A

formaldehyde-activating enzyme

$\mathrm{NAD}(\mathrm{P})^{+}$-dependent formaldehyde dehydrogenase

1,6-bisphosphate aldolase

methenyl- $\mathrm{H}_{4} \mathrm{~F}$ cyclohydrolase

formate dehydrogenase

S-formyl-GSH hydrolase

response regulator FlhR

signal regulator FlhS

formolase

F6P aldolase

formate-tetrahydrofolate ligase

glycolaldehyde synthase

NAD-GSH-dependent formaldehyde dehydrogenase

glutathione-dependent formaldehyde-activating enzyme

2-hydroxyacyl-CoA-lyase

HOB aldolase

HOB aminotransferase

4-hydroxy-2-oxobutanoate

hydroxypyruvate reductase

3-hexulose-6-phosphate synthase

homoserine kinase

isocitrate dehydrogenase

2-amino-3-ketobutyrate CoA ligase

Ara5P isomerase

threonine aldolase

methylamine dehydrogenase

malate dehydrogenase

malyl-CoA lyase

methanol dehydrogenase

methylene- $\mathrm{H}_{4} \mathrm{~F}$ dehydrogenase

malate thiokinase

6-phospho-3-hexuloisomerase

phosphoketolase

phosphoenolpyruvate synthetase

acetyltransferase

2-keto-3-deoxy-L-rhamnonate aldolase

Ru5P epimerase

Ri5P isomerase

allose 6-phosphate isomerase/ribose 5-phosphate isomerase B

serine aldolase

acid-soluble spore proteins

sedoheptulose-1,7-bisphosphatase

serine dehydratase

hydroxymethyltransferase

transaldolase

threonine dehydrogenase

transketolase

threonine synthase 


Pathways
GAA pathway
HC
MCC
MSC
NOG
PPP
RGP
RuMP cycle
SACA pathway
STC
TCA cycle
Other
ALE
EMRA
FBA

glycolaldehyde assimilation pathway

homoserine cycle

methanol condensation cycle

modified serine cycle

nonoxidative glycolysis

pentose phosphate pathway

reductive glycine pathway

ribulose monophosphate cycle

synthetic acetyl-CoA pathway

Serine-threonine cycle

tricarboxylic acid cycle

adaptive laboratory evolution

ensemble modelling for robustness analysis

flux balance analysis

\section{References}

1. Yurimoto, H.; Kato, N.; Sakai, Y. Assimilation, Dissimilation, and Detoxification of Formaldehyde, a Central Metabolic Intermediate of Methylotrophic Metabolism. Chem. Rec. 2005, 5, 367-375. [CrossRef]

2. Lowe, D.C.; Schmidt, U. Formaldehyde (HCHO) Measurements in the Nonurban Atmosphere. J. Geophys. Res. 1983, 88, 10844-10858. [CrossRef]

3. Luecken, D.J.; Hutzell, W.T.; Strum, M.L.; Pouliot, G.A. Regional Sources of Atmospheric Formaldehyde and Acetaldehyde, and Implications for Atmospheric Modeling. Atmos. Environ. 2012, 47, 477-490. [CrossRef]

4. Hun, D.E.; Corsi, R.L.; Morandi, M.T.; Siegel, J.A. Formaldehyde in Residences: Long-Term Indoor Concentrations and Influencing Factors. Indoor Air 2010, 20, 196-203. [CrossRef]

5. Gandhi, N.N.; Barrett-Wilt, G.; Steele, J.L.; Rankin, S.A. Lactobacillus casei Expressing Methylglyoxal Synthase Causes Browning and Heterocyclic Amine Formation in Parmesan Cheese Extract. J. Dairy Sci. 2019, 102, 100-112. [CrossRef]

6. Kamps, J.J.A.G.; Hopkinson, R.J.; Schofield, C.J.; Claridge, T.D.W. How Formaldehyde Reacts with Amino Acids. Commun. Chem. 2019, 2, 1-14. [CrossRef]

7. Auerbach, C.; Moutschen-Dahmen, M.; Moutschen, J. Genetic and Cytogenetical Effects of Formaldehyde and Related Compounds. Mutat. Res. 1977, 39, 317-361. [CrossRef]

8. Becerra, M.C.; Páez, P.L.; Laróvere, L.E.; Albesa, I. Lipids and DNA Oxidation in Staphylococcus aureus as a Consequence of Oxidative Stress Generated by Ciprofloxacin. Mol. Cell. Biochem. 2006, 285, 29-34. [CrossRef] [PubMed]

9. Imlay, J.A.; Chin, S.M.; Linn, S. Toxic DNA Damage by Hydrogen Peroxide through the Fenton Reaction in Vivo and in Vitro. Science. 1988, 240, 640-642. [CrossRef] [PubMed]

10. Sobles, F.H. Organic Peroxides and Mutagenic Effects in Drosophila: Mutagenicity of Dihydroxydimethyl Peroxide and the Mutagenic Effects of Formaldehyde. Nature 1956, 177, 979-980. [CrossRef]

11. Song, Z.B.; Xiao, S.Q.; You, L.; Wang, S.S.; Tan, H.; Li, K.Z.; Chen, L.M. C1 Metabolism and the Calvin Cycle Function Simultaneously and Independently during HCHO Metabolism and Detoxification in Arabidopsis thaliana Treated with HCHO Solutions. Plant, Cell Environ. 2013, 36, 1490-1506. [CrossRef]

12. Kelly, D.P.; Dewar, M.K.; Johns, R.B.; Wei-Let, S.; Yates, J.F. Cross-Linking of Amino Acids by Formaldehyde. Preparation and ${ }^{13} \mathrm{C}$ NMR Spectra of Model Compounds. Adv. Exp. Med. Biol. 1977, 86A, 641-647.

13. Metz, B.; Kersten, G.F.A.; Baart, G.J.E.; De Jong, A.; Meiring, H.; Ten Hove, J.; Van Steenbergen, M.J.; Hennink, W.E.; Crommelin, D.J.A.; Jiskoot, W. Identification of Formaldehyde-Induced Modifications in Proteins: Reactions with Insulin. Bioconjug. Chem. 2006, 17, 815-822. [CrossRef]

14. Kawanishi, M.; Matsuda, T.; Yagi, T. Genotoxicity of Formaldehyde: Molecular Basis of DNA Damage and Mutation. Front. Environ. Sci. 2014, 2, 36. [CrossRef]

15. Metz, B.; Kersten, G.F.A.; Hoogerhout, P.; Brugghe, H.F.; Timmermans, H.A.M.; De Jong, A.; Meiring, H.; Hove, J.; Hennink, W.E.; Crommelin, D.J.A.; et al. Identification of Formaldehyde-Induced Modifications in Proteins: Reactions with Model Peptides. J. Biol. Chem. 2004, 279, 6235-6243. [CrossRef] [PubMed]

16. Wilson, S.M.; Gleisten, M.P.; Donohue, T.J. Identification of Proteins Involved in Formaldehyde Metabolism by Rhodobacter sphaeroides. Microbiology 2008, 154, 296-305. [CrossRef]

17. Summers, R.M.; Louie, T.M.; Yu, C.L.; Gakhar, L.; Louie, K.C.; Subramanian, M. Novel, Highly Specific N-Demethylases Enable Bacteria to Live on Caffeine and Related Purine Alkaloids. J. Bacteriol. 2012, 194, 2041-2049. [CrossRef] [PubMed]

18. Venkatesagowda, B.; Dekker, R.F.H. Microbial Demethylation of Lignin: Evidence of Enzymes Participating in the Removal of Methyl/Methoxyl Groups. Enzyme Microb. Technol. 2021, 147, 1-26. [CrossRef]

19. Chen, N.H.; Djoko, K.Y.; Veyrier, F.J.; McEwan, A.G. Formaldehyde Stress Responses in Bacterial Pathogens. Front. Microbiol. 2016, 7, 1-17. [CrossRef] 
20. Anthony, C. The Biochemistry of Methylotrophs; Academic Press: London, UK; New York, NY, USA, 1982.

21. Heux, S.; Brautaset, T.; Vorholt, J.A.; Wendisch, V.F.; Portais, J.C. Synthetic Methylotrophy: Past, Present, and Future. In Methane Biocatalysis: Paving the Way to Sustainability; Springer International Publishing: Cham, Switzerland, 2018; pp. $133-151$.

22. Arfman, N.; Watling, E.M.; Clement, W.; Van Oosterwijk, R.J.; de Vries, G.E.; Harder, W.; Attwood, M.M.; Dijkhuizen, L. Methanol Metabolism in Thermotolerant Methylotrophic Bacillus Strains Involving a Novel Catabolic NAD-Dependent Methanol Dehydrogenase as a Key Enzyme. Arch Microbiol 1989, 152, 280-288. [CrossRef]

23. Kremp, F.; Volker, M. Methanol and Methyl Group Conversion in Acetogenic Bacteria: Biochemistry, Physiology and Application. FEMS Microbiol. Rev. 2020, 45, 1-22. [CrossRef]

24. Lee, J.A.; Riazi, S.; Nemati, S.; Bazurto, J.V.; Vasdekis, A.E.; Ridenhour, B.J.; Remien, C.H.; Marx, C.J. Microbial Phenotypic Heterogeneity in Response to a Metabolic Toxin: Continuous, Dynamically Shifting Distribution of Formaldehyde Tolerance in Methylobacterium extorquens Populations. PLoS Genet. 2019, 15, e1008458. [CrossRef] [PubMed]

25. Gao, B.; Zhao, N.; Deng, J.; Gu, Y.; Jia, S.; Hou, Y.; Lv, X.; Liu, L. Constructing a Methanol-Dependent Bacillus subtilis by Engineering the Methanol Metabolism. J. Biotechnol. 2022, 343, 128-137. [CrossRef]

26. Koopman, F.W.; De Winde, J.H.; Ruijssenaars, H.J. C1 Compounds as Auxiliary Substrate for Engineered Pseudomonas putida S12. Appl. Microbiol. Biotechnol. 2009, 83, 705-713. [CrossRef]

27. Chen, F.Y.H.; Jung, H.W.; Tsuei, C.Y.; Liao, J.C. Converting Escherichia coli to a Synthetic Methylotroph Growing Solely on Methanol. Cell 2020, 182, 933-946.e14. [CrossRef] [PubMed]

28. Kalyuzhnaya, M.G.; Xing, X.-H. Methane Biocatalysis: Paving the Way to Sustainability; Kalyuzhnaya, M.G., Xing, X.-H., Eds.; Springer International Publishing AG part of Springer Nature: Cham, Switzerland, 2018.

29. Vorholt, J.A. Cofactor-Dependent Pathways of Formaldehyde Oxidation in Methylotrophic Bacteria. Arch. Microbiol. 2002, 178, 239-249. [CrossRef] [PubMed]

30. Zhang, W.; Zhang, T.; Wu, S.; Wu, M.; Xin, F.; Dong, W.; Ma, J.; Zhang, M.; Jiang, M. Guidance for Engineering of Synthetic Methylotrophy Based on Methanol Metabolism in Methylotrophy. RSC Adv. 2017, 7, 4083-4091. [CrossRef]

31. Zhu, T.; Zhao, T.; Bankefa, O.E.; Li, Y. Engineering Unnatural Methylotrophic Cell Factories for Methanol-Based Biomanufacturing: Challenges and Opportunities. Biotechnol. Adv. 2020, 39, 1-10. [CrossRef] [PubMed]

32. Pfeifenschneider, J.; Brautaset, T.; Wendisch, V.F. Methanol as Carbon Substrate in the Bio-Economy: Metabolic Engineering of Aerobic Methylotrophic Bacteria for Production of Value-Added Chemicals. Biofuels Bioprod. Biorefining 2017, 11, 719-731. [CrossRef]

33. Tuyishime, P.; Sinumvayo, J.P. Novel Outlook in Engineering Synthetic Methylotrophs and Formatotrophs: A Course for Advancing C1-Based Chemicals Production. World J. Microbiol. Biotechnol. 2020, 36, 1-16. [CrossRef]

34. Guo, F.; Zhang, S.; Jiang, Y.; Xu, H.; Xin, F.; Zhang, W.; Jiang, M. Bioconversion of Methanol by Synthetic Methylotrophy. In Advances in Biochemical Engineering/Biotechnology; Springer: Berlin/Heidelberg, Germany, 2021. [CrossRef]

35. Jiang, W.; Villamor, D.H.; Peng, H.; Chen, J.; Liu, L.; Haritos, V.; Ledesma-amaro, R. Metabolic Engineering Strategies to Enable Microbial Utilization of C1 Feedstocks. Nat. Chem. Biol. 2021, 17, 845-855. [CrossRef] [PubMed]

36. Gregory, G.J.; Bennett, R.K.; Papoutsakis, E.T. Recent Advances toward the Bioconversion of Methane and Methanol in Synthetic Methylotrophs. Metab. Eng. 2021. ePublished ahead of print. [CrossRef]

37. Yang, D.; Park, S.Y.; Park, Y.S.; Eun, H.; Lee, S.Y. Metabolic Engineering of Escherichia coli for Natural Product Biosynthesis. Trends Biotechnol. 2020, 38, 745-765. [CrossRef] [PubMed]

38. Wolf, S.; Becker, J.; Tsuge, Y.; Kawaguchi, H.; Kondo, A.; Marienhagen, J.; Bott, M.; Wendisch, V.F.; Wittmann, C. Advances in Metabolic Engineering of Corynebacterium glutamicum to Produce High-Value Active Ingredients for Food, Feed, Human Health, and Well-Being. Essays Biochem. 2021, 65, 197-212.

39. Vorholt, J.A.; Chistoserdova, L.; Stolyar, S.M.; Thauer, R.K.; Lidstrom, M.E. Distribution of Tetrahydromethanopterin-Dependent Enzymes in Methylotrophic Bacteria and Phylogeny of Methenyl Tetrahydromethanopterin Cyclohydrolases. J. Bacteriol. 1999, 181, 5750-5757. [CrossRef] [PubMed]

40. Ras, J.; Van Ophem, P.W.; Reijnders, W.N.M.; Van Spanning, R.J.M.; Duine, J.A.; Stouthamer, A.H.; Harms, N. Isolation, Sequencing, and Mutagenesis of the Gene Encoding NAD- and Glutathione-Dependent Formaldehyde Dehydrogenase (GD-FALDH) from Paracoccus denitrificans, in Which GD-FALDH Is Essential for Methylotrophic Growth. J. Bacteriol. 1995, 177, 247-251. [CrossRef]

41. Vorholt, J.A.; Chistoserdova, L.; Lidstrom, M.E.; Thauer, R.K. The NADP-Dependent Methylene Tetrahydromethanopterin Dehydrogenase in Methylobacterium extorquens AM1. J. Bacteriol. 1998, 180, 5351-5356. [CrossRef] [PubMed]

42. Pomper, B.K.; Vorholt, J.A.; Chistoserdova, L.; Lidstrom, M.E.; Thauer, R.K. A Methenyl Tetrahydromethanopterin Cyclohydrolase and a Methenyl Tetrahydrofolate Cyclohydrolase in Methylobacterium extorquens AM1. Eur. J. Biochem. 1999, 261, 475-480. [CrossRef] [PubMed]

43. Goenrich, M.; Bursy, J.; Hübner, E.; Linder, D.; Schwartz, A.C.; Vorholt, J.A. Purification and Characterization of the Methylene Tetrahydromethanopterin Dehydrogenase MtdB and the Methylene Tetrahydrofolate Dehydrogenase FolD from Hyphomicrobium zavarzinii ZV580. Arch. Microbiol. 2002, 177, 299-303. [CrossRef]

44. Chistoserdova, L.; Gomelsky, L.; Vorholt, J.A.; Gomelsky, M.; Tsygankov, Y.D.; Lidstrom, M.E. Analysis of Two Formaldehyde Oxidation Pathways in Methylobacillus flagellatus KT, a Ribulose Monophosphate Cycle Methylotroph. Microbiology 2000, 146, 233-238. [CrossRef] 
45. Müller, J.E.N.; Meyer, F.; Litsanov, B.; Kiefer, P.; Vorholt, J.A. Core Pathways Operating during Methylotrophy of Bacillus methanolicus MGA3 and Induction of a Bacillithiol-Dependent Detoxification Pathway upon Formaldehyde Stress. Mol. Microbiol. 2015, 98, 1089-1100. [CrossRef]

46. Heggeset, T.M.B.; Krog, A.; Balzer, S.; Wentzel, A.; Ellingsen, T.E.; Brautaseta, T. Genome Sequence of Thermotolerant Bacillus methanolicus: Features and Regulation Related to Methylotrophy and Production of L-Lysine and L-Glutamate from Methanol. Appl. Environ. Microbiol. 2012, 78, 5170-5181. [CrossRef] [PubMed]

47. Müller, J.E.N.; Litsanov, B.; Bortfeld-Miller, M.; Trachsel, C.; Grossmann, J.; Brautaset, T.; Vorholt, J.A. Proteomic Analysis of the Thermophilic Methylotroph Bacillus methanolicus MGA3. Proteomics 2014, 14, 725-737. [CrossRef] [PubMed]

48. Marx, C.J.; Lidstrom, M.E. Development of an Insertional Expression Vector System for Methylobacterium extorquens AM1 and Generation of Null Mutants Lacking MtdA and/or Fch. Microbiology 2004, 150, 9-19. [CrossRef] [PubMed]

49. Crowther, G.J.; Kosály, G.; Lidstrom, M.E. Formate as the Main Branch Point for Methylotrophic Metabolism in Methylobacterium extorquens AM1. J. Bacteriol. 2008, 190, 5057-5062. [CrossRef] [PubMed]

50. Vorholt, J.A.; Marx, C.J.; Lidstrom, M.E.; Thauer, R.K. Novel Formaldehyde-Activating Enzyme in Methylobacterium extorquens AM1 Required for Growth on Methanol. J. Bacteriol. 2000, 182, 6645-6650. [CrossRef]

51. Yanpirat, P.; Nakatsuji, Y.; Hiraga, S.; Fujitani, Y.; Izumi, T.; Masuda, S.; Mitsui, R.; Nakagawa, T.; Tani, A. Lanthanide-Dependent Methanol and Formaldehyde Oxidation in Methylobacterium aquaticum Strain 22A. Microorganisms 2020, 8, 822. [CrossRef]

52. Ten, L.N.; Li, W.; Salah, N.; Myung, E.; Kim, K.; Yeol, S.; Alejandro, L. Methylobacterium segetis Sp. Nov., a Novel Member of the Family Methylobacteriaceae Isolated from Soil on Jeju Island. Arch. Microbiol. 2020, 202, 747-754. [CrossRef]

53. Chou, H.-H.; Chiu, H.-C.; Delaney, N.F.; Segrè, D.; Marx, C.J. Diminishing Returns Epistasis among Beneficial Mutations Decelerates Adaptation. Science. 2011, 332, 1190-1192. [CrossRef]

54. Harms, N.; Ras, J.; Koning, S.; Reijnders, W.N.M.; Stouthamer, A.H.; Van Spanning, R.J.M. Genetics of C1 Metabolism Regulation in Paracoccus Denitrificans. In Microbial Growth on C1 Compounds; Springer: Dordrecht, The Netherlands, 1996 ; pp. 126-132.

55. Goenrich, M.; Bartoschek, S.; Hagemeier, C.H.; Griesinger, C.; Vorholt, J.A. A Glutathione-Dependent Formaldehyde-Activating Enzyme (Gfa) from Paracoccus denitrificans Detected and Purified via Two-Dimensional Proton Exchange NMR. J. Biol. Chem. 2002, 277, 3069-3072. [CrossRef]

56. Marx, C.J.; Chistoserdova, L.; Lidstrom, M.E. Formaldehyde-Detoxifying Role of the Tetrahydromethanopterin-Linked Pathway in Methylobacterium extorquens AM1. J. Bacteriol. 2003, 185, 7160-7168. [CrossRef] [PubMed]

57. Barber, R.D.; Rott, M.A.; Donohue, T.J. Characterization of a Glutathione-Dependent Formaldehyde Dehydrogenase from Rhodobacter sphaeroides. J. Bacteriol. 1996, 178, 1386-1393. [CrossRef] [PubMed]

58. Barber, R.D.; Donohue, T.J. Function of a Glutathione-Dependent Formaldehyde Dehydrogenase in Rhodobacter sphaeroides Formaldehyde Oxidation and Assimilation. Biochemistry 1998, 37, 530-537. [CrossRef] [PubMed]

59. Harms, N.; Ras, J.; Reijnders, W.N.M.; Van Spanning, R.J.M.; Stouthamer, A.H. S-Formylglutathione Hydrolase of Paracoccus denitrificans Is Homologous to Human Esterase D: A Universal Pathway for Formaldehyde Detoxification? J. Bacteriol. 1996, 178, 6296-6299. [CrossRef]

60. Sahm, H.; Cox, R.B.; Quayle, J.R. Metabolism of Methanol by Rhodopseudomonas acidophila. J. Gen. Microbiol. 1976, 94, 313-322. [CrossRef] [PubMed]

61. Misset-Smits, M.; Van Ophem, P.W.; Sakuda, S.; Duine, J.A. Mycothiol, 1-O-(2'-[N-Acetyl-L-Cysteinyl]Amido-2'-Deoxy- $\alpha$-DGlucopyranosyl)-D-Myo -Inositol, Is the Factor of NAD/Factor-Dependent Formaldehyde Dehydrogenase. FEBS Lett. 1997, 409, 221-222. [CrossRef]

62. Eggeling, L.; Sahm, H. A Trimeric Enzyme Requiring a Cofactor and Active with Alcohols. Eur. J. Biochem. 1985, 150, 129-134 [CrossRef]

63. van Ophem, P.W.; van Beeumen, J.; Duine, J.A. NAD-linked, Factor-dependent Formaldehyde Dehydrogenase or Trimeric, Zinc-containing, Long-chain Alcohol Dehydrogenase from Amycolatopsis methanolica. Eur. J. Biochem. 1992, 206, 511-518. [CrossRef]

64. Klein, C.R.; Kesseler, F.P.; Perrei, C.; Frank, J.; Duine, J.A.; Schwartz, A.C. A Novel Dye-Linked Formaldehyde Dehydrogenase with Some Properties Indicating the Presence of a Protein-Bound Redox-Active Quinone Cofactor. Biochem. J. 1994, 301, 289-295. [CrossRef]

65. Zahn, J.A.; Bergmann, D.J.; Boyd, J.M.; Kunz, R.C.; DiSpirito, A.A. Membrane-Associated Quinoprotein Formaldehyde Dehydrogenase from Methylococcus capsulatus Bath. J. Bacteriol. 2001, 183, 6832-6840. [CrossRef]

66. Schmidt, S.; Christen, P.; Kiefer, P.; Vorholt, J.A. Functional Investigation of Methanol Dehydrogenase-like Protein XoxF in Methylobacterium extorquens AM1. Microbiology 2010, 156, 2575-2586. [CrossRef] [PubMed]

67. Pol, A.; Barends, T.R.M.; Dietl, A.; Khadem, A.F.; Eygensteyn, J.; Jetten, M.S.M.; Op den Camp, H.J.M. Rare Earth Metals Are Essential for Methanotrophic Life in Volcanic Mudpots. Environ. Microbiol. 2014, 16, 255-264. [CrossRef] [PubMed]

68. Good, N.M.; Moore, R.S.; Suriano, C.J.; Martinez-Gomez, N.C. Contrasting in Vitro and in Vivo Methanol Oxidation Activities of Lanthanide-Dependent Alcohol Dehydrogenases XoxF1 and ExaF from Methylobacterium extorquens AM1. Sci. Rep. 2019, 9, 1-12. [CrossRef]

69. Skovran, E.; Palmer, A.D.; Rountree, A.M.; Good, N.M.; Lidstrom, M.E. XoxF Is Required for Expression of Methanol Dehydrogenase in Methylobacterium extorquens AM1. J. Bacteriol. 2011, 193, 6032-6038. [CrossRef] 
70. De Zwart, J.M.M.; Nelisse, P.N.; Kuenen, J.G. Isolation and Characterization of Methylophaga sulfidovorans Sp. Nov.: An Obligately Methylotrophic, Aerobic, Dimethylsulfide Oxidizing Bacterium from a Microbial Mat. FEMS Microbiol. Ecol. 1996, 20 , $261-270$. [CrossRef]

71. Delépine, B.; López, M.G.; Carnicer, M.; Vicente, C.M.; Wendisch, V.F.; Heux, S. Charting the Metabolic Landscape of the Facultative Methylotroph Bacillus methanolicus. mSystems 2020, 5, e00745-20. [CrossRef] [PubMed]

72. Chistoserdova, L.; Kalyuzhnaya, M.G.; Lidstrom, M.E. The Expanding World of Methylotrophic Metabolism. Annu. Rev. Microbiol. 2009, 63, 477-499. [CrossRef] [PubMed]

73. Vargas, D.; Hageman, S.; Gulati, M.; Nobile, C.J.; Rawat, M. S-Nitrosomycothiol Reductase and Mycothiol Are Required for Survival under Aldehyde Stress and Biofilm Formation in Mycobacterium smegmatis. IUBMB Life 2016, 68, 621-628. [CrossRef]

74. Mitsui, R.; Kusano, Y.; Yurimoto, H.; Sakai, Y.; Kato, N.; Tanaka, M. Formaldehyde Fixation Contributes to Detoxification for Growth of a Nonmethylotroph, Burkholderia cepacia TM1, on Vanillic Acid. Appl. Environ. Microbiol. 2003, 69, 6128-6132. [CrossRef]

75. Tanaka, N.; Kusakabe, Y.; Ito, K.; Yoshimoto, T.; Nakamura, K.T. Crystal Structure of Glutathione-Independent Formaldehyde Dehydrogenase. Chem. Biol. Interact. 2003, 143-144, 211-218. [CrossRef]

76. Marx, C.J.; Miller, J.A.; Chistoserdova, L.; Lidstrom, M.E. Multiple Formaldehyde Oxidation/Detoxification Pathways in Burkholderia Fungorum LB400. J. Bacteriol. 2004, 186, 2173-2178. [CrossRef] [PubMed]

77. Liao, Y.; Chen, S.; Wang, D.; Zhang, W.; Wang, S.; Ding, J.; Wang, Y.; Cai, L.; Ran, X.; Wang, X.; et al. Structure of Formaldehyde Dehydrogenase from Pseudomonas aeruginosa: The Binary Complex with the Cofactor NAD +. Struct. Biol. Cryst. Commun. 2013, 69, 967-972. [CrossRef]

78. Ando, M.; Yoshtmoto, T.; Ogushl, S.; Rikitake, K.; Shibata, S.; Tsuru, D. Formaldehyde Dehydrogenase from Pseudomonas putida: Purification and Some Properties. J. Biochem. 1979, 85, 1165-1172.

79. Kato, N.; Shirakawa, K.; Kobayashi, H.; Sakazawa, C. The Dismutation of Aldehydes by a Bacterial Enzyme. Agric. Biol. Chem. $1983,47,39-46$.

80. Bystrykh, L.V.; Govorukhina, N.I.; Van Ophem, P.W.; Hektor, H.J.; Dijkhuizen, L.; Duine, J.A. Formaldehyde Dismutase Activities in Gram-Positive Bacteria Oxidizing Methanol. J. Gen. Microbiol. 1993, 139, 1979-1985. [CrossRef]

81. Nguyen, T.T.H.; Eiamphungporn, W.; Mäder, U.; Liebeke, M.; Lalk, M.; Hecker, M.; Helmann, J.D.; Antelmann, H. Genome-Wide Responses to Carbonyl Electrophiles in Bacillus subtilis: Control of the Thiol-Dependent Formaldehyde Dehydrogenase AdhA and Cysteine Proteinase YraA by the MerR-Family Regulator YraB (AdhR). Mol. Microbiol. 2009, 71, 876-894.

82. Loshon, C.A.; Genest, P.C.; Setlow, B.; Setlow, P. Formaldehyde Kills Spores of Bacillus subtilis by DNA Damage and Small, Acid-Soluble Spore Proteins of the $\alpha / \beta$-Type Protect Spores against This DNA Damage. J. Appl. Microbiol. 1999, 87, 8-14. [CrossRef]

83. Moeller, R.; Vlašić, I.; Reitz, G.; Nicholson, W.L. Role of Altered RpoB Alleles in Bacillus subtilis Sporulation and Spore Resistance to Heat, Hydrogen Peroxide, Formaldehyde, and Glutaraldehyde. Arch. Microbiol. 2012, 194, 759-767. [CrossRef]

84. Newton, G.L.; Rawat, M.; La Clair, J.J.; Jothivasan, V.K.; Budiarto, T.; Hamilton, C.J.; Claiborne, A.; Helmann, J.D.; Fahey, R.C. Bacillithiol Is an Antioxidant Thiol Produced in Bacilli. Nat. Chem. Biol. 2009, 5, 625-627. [CrossRef]

85. Yasueda, H.; Kawahara, Y.; Sugimoto, S.I. Bacillus subtilis yckG and yckF Encode Two Key Enzymes of the Ribulose Monophosphate Pathway Used by Methylotrophs, and yckH Is Required for Their Expression. J. Bacteriol. 1999, 181, 7154-7160. [CrossRef] [PubMed]

86. Yurimoto, H.; Hirai, R.; Matsuno, N.; Yasueda, H.; Kato, N.; Sakai, Y. HxlR, a Member of the DUF24 Protein Family, Is a DNA-Binding Protein That Acts as a Positive Regulator of the Formaldehyde-Inducible hxlAB Operon in Bacillus subtilis. Mol. Microbiol. 2005, 57, 511-519. [CrossRef]

87. Gaballa, A.; Antelmann, H.; Hamilton, C.J.; Helmann, J.D. Regulation of Bacillus subtilis Bacillithiol Biosynthesis Operons by Spx. Microbiol. 2013, 159, 2025-2035. [CrossRef]

88. Witthoff, S.; Schmitz, K.; Niedenführ, S.; Nöh, K.; Noack, S.; Bott, M.; Marienhagen, J. Metabolic Engineering of Corynebacterium glutamicum for Methanol Metabolism. Appl. Environ. Microbiol. 2015, 81, 2215-2225. [CrossRef]

89. Hennig, G.; Haupka, C.; Brito, L.F.; Rückert, C.; Cahoreau, E.; Heux, S.; Wendisch, V.F. Methanol-Essential Growth of Corynebacterium glutamicum: Adaptive Laboratory Evolution Overcomes Limitation Due to Methanethiol Assimilation Pathway. Int. J. Mol. Sci. 2020, 21, 3617. [CrossRef] [PubMed]

90. Witthoff, S.; Mühlroth, A.; Marienhagen, J.; Bott, M. C1 Metabolism in Corynebacterium glutamicum: An Endogenous Pathway for Oxidation of Methanol to Carbon Dioxide. Appl. Environ. Microbiol. 2013, 79, 6974-6983. [CrossRef] [PubMed]

91. Lessmeier, L.; Hoefener, M.; Wendisch, V.F. Formaldehyde Degradation in Corynebacterium glutamicum Involves Acetaldehyde Dehydrogenase and Mycothiol-Dependent Formaldehyde Dehydrogenase. Microbiology 2013, 159, 2651-2662. [CrossRef]

92. Witthoff, S.; Eggeling, L.; Bott, M.; Polen, T. Corynebacterium glutamicum Harbours a Molybdenum Cofactor-Dependent Formate Dehydrogenase Which Alleviates Growth Inhibition in the Presence of Formate. Microbiology 2012, 158, 2428-2439. [CrossRef]

93. Leßmeier, L.; Pfeifenschneider, J.; Carnicer, M.; Heux, S.; Portais, J.C.; Wendisch, V.F. Production of Carbon-13-Labeled Cadaverine by Engineered Corynebacterium glutamicum Using Carbon-13-Labeled Methanol as Co-Substrate. Appl. Microbiol. Biotechnol. 2015, 99, 10163-10176. [CrossRef]

94. Tuyishime, P.; Wang, Y.; Fan, L.; Zhang, Q.; Li, Q.; Zheng, P.; Sun, J.; Ma, Y. Engineering Corynebacterium glutamicum for Methanol-Dependent Growth and Glutamate Production. Metab. Eng. 2018, 49, 220-231. [CrossRef] [PubMed] 
95. Wang, Y.; Liu, Y.; Liu, J.; Guo, Y.; Fan, L.; Ni, X.; Zheng, X.; Wang, M.; Zheng, P.; Sun, J.; et al. MACBETH: Multiplex Automated Corynebacterium glutamicum Base Editing Method. Metab. Eng. 2018, 47, 200-210. [CrossRef]

96. Gutheil, W.G.; Holmquist, B.; Vallee, B.L. Purification, Characterization, and Partial Sequence of the Glutathione-Dependent Formaldehyde Dehydrogenase from Escherichia coli: A Class III Alcohol Dehydrogenase. Biochemistry 1992, 31, 475-481. [CrossRef]

97. Gutheil, W.G.; Kasimoglu, E.; Nicholson, P.C. Induction of Glutathione-Dependent Formaldehyde Dehydrogenase Activity in Escherichia coli and Hemophilus influenza. Biochem. Biophys. Res. Commun. 1997, 238, 693-696. [CrossRef]

98. Herring, C.D.; Blattner, F.R. Global Transcriptional Effects of a Suppressor TRNA and the Inactivation of the Regulator FrmR. J. Bacteriol. 2004, 186, 6714-6720. [CrossRef]

99. Gonzalez, C.F.; Proudfoot, M.; Brown, G.; Korniyenko, Y.; Mori, H.; Savchenko, A.V.; Yakunin, A.F. Molecular Basis of Formaldehyde Detoxification: Characterization of Two S-Formylglutathione Hydrolases from Escherichia coli, FrmB and YeiG. J. Biol. Chem. 2006, 281, 14514-14522. [CrossRef]

100. Mason, R.P.; Sanders, J.K.M.; Crawford, A.; Hunter, B.K. Formaldehyde Metabolism by Escherichia coli. Detection by in Vivo ${ }^{13}$ C NMR Sectroscopy of S-(Hydroxymethyl)Glutathione as a Transient Intracellular Intermediate. Biochemistry 1986, 25, $4504-4507$. [CrossRef] [PubMed]

101. De Simone, A.; Vicente, C.M.; Peiro, C.; Gales, L.; Bellvert, F.; Enjalbert, B.; Heux, S. Mixing and Matching Methylotrophic Enzymes to Design a Novel Methanol Utilization Pathway in E. coli. Metab. Eng. 2020, 61, 315-325. [CrossRef] [PubMed]

102. Zhang, W.; Zhang, T.; Song, M.; Dai, Z.; Zhang, S.; Xin, F.; Dong, W.; Ma, J.; Jiang, M. Metabolic Engineering of Escherichia coli for High Yield Production of Succinic Acid Driven by Methanol. ACS Synth. Biol. 2018, 7, 2803-2811. [CrossRef]

103. Price, J.V.; Chen, L.; Whitaker, W.B.; Papoutsakis, E.; Chen, W. Scaffoldless Engineered Enzyme Assembly for Enhanced Methanol Utilization. Proc. Natl. Acad. Sci. USA 2016, 113, 12691-12696. [CrossRef] [PubMed]

104. Bennett, R.K.; Agee, A.; Har, J.R.G.; von Hagel, B.; Antoniewicz, M.R.; Papoutsakis, E.T. Regulatory Interventions Improve the Biosynthesis of Limiting Amino Acids from Methanol Carbon to Improve Synthetic Methylotrophy in Escherichia coli. Biotechnol. Bioeng. 2021, 118, 43-57. [CrossRef]

105. Bennett, R.K.; Agee, A.; Ren, J.; Har, G.; Von Hagel, B.; Siu, K.; Antoniewicz, M.R.; Papoutsakis, E.T. Triggering the Stringent Response Enhances Synthetic Methanol Utilization in Escherichia Coli. Metab. Eng. 2020, 61, 1-10. [CrossRef]

106. Bennett, R.K.; Dillon, M.; Ren, J.; Har, G.; Agee, A.; Von Hagel, B.; Rohlhill, J.; Antoniewicz, M.R.; Papoutsakis, E.T. Engineering Escherichia coli for Methanol-Dependent Growth on Glucose for Metabolite Production. Metab. Eng. 2020, 60, 45-55. [CrossRef]

107. Wang, J.; Jian, X.; Xing, X.; Zhang, C.; Fei, Q. Empowering a Methanol-Dependent Escherichia coli via Adaptive Evolution Using a High-Throughput Microbial Microdroplet Culture System. Front. Bioeng. Biotechnol. 2020, 8, 570. [CrossRef] [PubMed]

108. Bennett, R.K.; Gregory, G.J.; Gonzalez, J.E.; Ren, J.; Har, G.; Antoniewicz, M.R.; Papoutsakis, E.T. Improving the Methanol Tolerance of an Escherichia coli Methylotroph via Adaptive Laboratory Evolution Enhances Synthetic Methanol Utilization. Front. Microbiol. 2021, 12, 638426. [CrossRef] [PubMed]

109. Bennett, R.K.; Dzvova, N.; Dillon, M.; Jones, S.; Hestmark, K.; Zhu, B.; Helman, N.; Greenfield, D.; Clarke, E.; Papoutsakis, E.T. Expression of Soluble Methane Monooxygenase in Escherichia coli Enables Methane Conversion. bioRxiv 2021.

110. He, H.; Höper, R.; Dodenhöft, M.; Marlière, P.; Bar-Even, A. An Optimized Methanol Assimilation Pathway Relying on Promiscuous Formaldehyde-Condensing Aldolases in E. coli. Metab. Eng. 2020, 60, 1-13. [CrossRef] [PubMed]

111. Wang, C.; Ren, J.; Zhou, L.; Li, Z.; Chen, L.; Zeng, A. An Aldolase-Catalyzed New Metabolic Pathway for the Assimilation of Formaldehyde and Methanol to Synthesize 2-Keto-4- Hydroxybutyrate and 1,3-Propanediol in Escherichia coli. ACS Synth. Biol. 2019, 8, 2483-2493. [CrossRef]

112. Gonzalez, J.E.; Bennett, R.K.; Papoutsakis, E.T.; Antoniewicz, M.R. Methanol Assimilation in Escherichia coli Is Improved by Co-Utilization of Threonine and Deletion of Leucine-Responsive Regulatory Protein. Metab. Eng. 2018, 45, 67-74. [CrossRef]

113. Wang, X.; Wang, Y.; Liu, J.; Li, Q.; Zhang, Z.; Zheng, P.; Lu, F. Biological Conversion of Methanol by Evolved Escherichia coli Carrying a Linear Methanol Assimilation Pathway. Bioresour. Bioprocess 2017, 4, 41. [CrossRef]

114. Chou, A.; Clomburg, J.M.; Qian, S.; Gonzalez, R. 2-Hydroxyacyl-CoA Lyase Catalyzes Acyloin Condensation for One-Carbon Bioconversion. Nat. Chem. Biol. 2019, 15, 900-906. [CrossRef] [PubMed]

115. Woolston, B.M.; King, J.R.; Reiter, M.; Van Hove, B.; Stephanopoulos, G. Improving Formaldehyde Consumption Drives Methanol Assimilation in Engineered E. coli. Nat. Commun. 2018, 9, 1-12. [CrossRef]

116. Chen, C.T.; Chen, F.Y.H.; Bogorad, I.W.; Wu, T.Y.; Zhang, R.; Lee, A.S.; Liao, J.C. Synthetic Methanol Auxotrophy of Escherichia coli for Methanol-Dependent Growth and Production. Metab. Eng. 2018, 49, 257-266. [CrossRef] [PubMed]

117. Meyer, F.; Keller, P.; Hartl, J.; Gröninger, O.G.; Kiefer, P.; Vorholt, J.A. Methanol-Essential Growth of Escherichia coli. Nat. Commun. 2018, 9, 1-10. [CrossRef] [PubMed]

118. Rohlhill, J.; Gerald Har, J.R.; Antoniewicz, M.R.; Papoutsakis, E.T. Improving Synthetic Methylotrophy via Dynamic Formaldehyde Regulation of Pentose Phosphate Pathway Genes and Redox Perturbation. Metab. Eng. 2020, 57, 247-255. [CrossRef] [PubMed]

119. Bennett, R.K.; Gonzalez, J.E.; Whitaker, W.B.; Antoniewicz, M.R.; Papoutsakis, E.T. Expression of Heterologous Non-Oxidative Pentose Phosphate Pathway from Bacillus methanolicus and Phosphoglucose Isomerase Deletion Improves Methanol Assimilation and Metabolite Production by a Synthetic Escherichia coli Methylotroph. Metab. Eng. 2018, 45, 75-85. [CrossRef] [PubMed]

120. Whitaker, W.B.; Jones, J.A.; Bennett, R.K.; Gonzalez, J.E.; Vernacchio, V.R.; Collins, S.M.; Palmer, M.A.; Schmidt, S.; Antoniewicz, M.R.; Koffas, M.A.; et al. Engineering the Biological Conversion of Methanol to Specialty Chemicals in Escherichia coli. Metab. Eng. 2017, 39, 49-59. [CrossRef] [PubMed] 
121. Müller, J.E.N.; Meyer, F.; Litsanov, B.; Kiefer, P.; Potthoff, E.; Heux, S.; Quax, W.J.; Wendisch, V.F.; Brautaset, T.; Portais, J.C.; et al. Engineering Escherichia coli for Methanol Conversion. Metab. Eng. 2015, 28, 190-201. [CrossRef] [PubMed]

122. Mitsui, R.; Sakai, Y.; Yasueda, H.; Kato, N. A Novel Operon Encoding Formaldehyde Fixation: The Ribulose Monophosphate Pathway in the Gram-Positive Facultative Methylotrophic Bacterium Mycobacterium gastri MB19. J. Bacteriol. 2000, 182, 944-948. [CrossRef] [PubMed]

123. Alves, A.M.C.R.; Euverink, G.J.W.; Hektor, H.J.; Hessels, G.I.; Van der Vlag, J.; Vrijbloed, J.W.; Hondmann, D.; Visser, J.; Dijkhuizen, L. Enzymes of Glucose and Methanol Metabolism in the Actinomycete Amycolatopsis methanolica. J. Bacteriol. 1994, 176, 6827-6835. [CrossRef] [PubMed]

124. Ferenci, T.; Strom, T.; Quayle, J.R. Purification and Properties of 3 Hexulose Phosphate Synthase and Phospho 3 Hexuloisomerase from Methylococcus capsulatus. Biochem. J. 1974, 144, 477-486. [CrossRef] [PubMed]

125. Hazeu, W.; de Bruyn, J.C.; van Dijken, J.P. Nocardia Sp. 239, a Facultative Methanol Utilizer with the Ribulose Monophosphate Pathway of Formaldehyde Fixation. Arch. Microbiol. 1983, 135, 205-210.

126. Sakai, Y.; Mitsui, R.; Katayama, Y.; Yanase, H.; Kato, N. Organization of the Genes Involved in the Ribulose Monophosphate Pathway in an Obligate Methylotrophic Bacterium, Methylomonas aminofaciens 77a. FEMS Microbiol. Lett. 1999, 176, 125-130. [CrossRef]

127. Yanase, H.; Ikeyama, K.; Mitsui, R.; Ra, S.; Kita, K.; Sakai, Y.; Kato, N. Cloning and Sequence Analysis of the Gene Encoding 3-Hexulose-6-Phosphate Synthase from the Methylotrophic Bacterium, Methylomonas aminofaciens 77a, and Its Expression in Escherichia coli. FEMS Microbiol. Lett. 1996, 135, 201-205. [CrossRef]

128. Chistoserdova, L.; Lapidus, A.; Han, C.; Goodwin, L.; Saunders, L.; Brettin, T.; Tapia, R.; Gilna, P.; Lucas, S.; Richardson, P.M.; et al. Genome of Methylobacillus flagellatus, Molecular Basis for Obligate Methylotrophy, and Polyphyletic Origin of Methylotrophy. J. Bacteriol. 2007, 189, 4020-4027. [CrossRef]

129. Hendrickson, E.L.; Beck, D.A.C.; Wang, T.; Lidstrom, M.E.; Hackett, M.; Chistoserdova, L. Expressed Genome of Methylobacillus flagellatus as Defined through Comprehensive Proteomics and New Insights into Methylotrophy. J. Bacteriol. 2010, 192, $4859-4867$. [CrossRef]

130. Whitaker, W.B.; Sandoval, N.R.; Bennett, R.K.; Fast, A.G.; Papoutsakis, E.T. Synthetic Methylotrophy: Engineering the Production of Biofuels and Chemicals Based on the Biology of Aerobic Methanol Utilization. Curr. Opin. Biotechnol. 2015, 33, 165-175. [CrossRef] [PubMed]

131. Dijkhuizen, L.; Levering, P.R.; Vries, G.E. Methane and Methanol Utilizers: The Physiology and Biochemistry of Aerobic MethanolUtilizing Gram-Negative Bacteria. In Biotechnology Handbooks; Colin Murrell, J., Dalton, H., Eds.; Springer: Boston, MA, USA, 1992; pp. 149-181.

132. Stolzenberger, J.; Lindner, S.N.; Persicke, M.; Brautaset, T.; Wendisch, V.F. Characterization of Fructose 1,6-Bisphosphatase and Sedoheptulose 1,7-Bisphosphatase from the Facultative Ribulose Monophosphate Cycle Methylotroph Bacillus methanolicus. J. Bacteriol. 2013, 195, 5112-5122. [CrossRef]

133. Jakobsen, Ø.M.; Benichou, A.; Flickinger, M.C.; Valla, S.; Ellingsen, T.E.; Brautaset, T. Upregulated Transcription of Plasmid and Chromosomal Ribulose Monophosphate Pathway Genes Is Critical for Methanol Assimilation Rate and Methanol Tolerance in the Methylotrophic Bacterium Bacillus methanolicus. J. Bacteriol. 2006, 188, 3063-3072. [CrossRef] [PubMed]

134. Pfeifenschneider, J.; Markert, B.; Stolzenberger, J.; Brautaset, T.; Wendisch, V.F. Transaldolase in Bacillus methanolicus: Biochemical Characterization and Biological Role in Ribulose Monophosphate Cycle. BMC Microbiol. 2020, 1-13. [CrossRef]

135. Krog, A.; Heggeset, T.M.B.; Müller, J.E.N.; Kupper, C.E.; Schneider, O.; Vorholt, J.A.; Ellingsen, T.E.; Brautaset, T. Methylotrophic Bacillus methanolicus Encodes Two Chromosomal and One Plasmid Born NAD+ Dependent Methanol Dehydrogenase Paralogs with Different Catalytic and Biochemical Properties. PLoS ONE 2013, 8, e59188. [CrossRef]

136. Fan, L.; Wang, Y.; Tuyishime, P.; Gao, N.; Li, Q.; Zheng, P.; Sun, J.; Ma, Y. Engineering Artificial Fusion Proteins for Enhanced Methanol Bioconversion. ChemBioChem 2018, 19, 2465-2471. [CrossRef] [PubMed]

137. Orita, I.; Sakamoto, N.; Kato, N. Bifunctional Enzyme Fusion of 3-Hexulose-6-Phosphate Synthase and 6-Phospho-3Hexuloisomerase. Appl. Microbiol. Biotechnol. 2007, 76, 439-445. [CrossRef] [PubMed]

138. Wang, Y.; Fan, L.; Tuyishime, P.; Liu, J.; Zhang, K.; Gao, N.; Zhang, Z.; Ni, X.; Feng, J.; Yuan, Q.; et al. Adaptive Laboratory Evolution Enhances Methanol Tolerance and Conversion in Engineered Corynebacterium glutamicum. Commun. Biol. 2020, 3, 1-15. [CrossRef] [PubMed]

139. He, H.; Edlich-Muth, C.; Lindner, S.N.; Bar-Even, A. Ribulose Monophosphate Shunt Provides Nearly All Biomass and Energy Required for Growth of E. coli. ACS Synth. Biol. 2018, 7, 1601-1611. [CrossRef]

140. Lee, Y.; Lafontaine, J.G.; Liao, J.C. Ensemble Modeling for Robustness Analysis in Engineering Non-Native Metabolic Pathways. Metab. Eng. 2014, 25, 63-71. [CrossRef] [PubMed]

141. Keller, P.; Noor, E.; Meyer, F.; Reiter, M.A.; Anastassov, S.; Kiefer, P.; Vorholt, J.A. Methanol-Dependent Escherichia coli Strains with a Complete Ribulose Monophosphate Cycle. Nat. Commun. 2020, 11, 5430. [CrossRef] [PubMed]

142. Leßmeier, L.; Wendisch, V.F. Identification of Two Mutations Increasing the Methanol Tolerance of Corynebacterium glutamicum. BMC Microbiol. 2015, 15, 1-11. [CrossRef]

143. Wang, X.; Wang, X.; Lu, X.; Ma, C.; Chen, K.; Ouyang, P. Methanol Fermentation Increases the Production of NAD(P)H-Dependent Chemicals in Synthetic Methylotrophic Escherichia coli. Biotechnol. Biofuels 2019, 12, 17. [CrossRef] 
144. Bogorad, I.W.; Chen, C.T.; Theisen, M.K.; Wu, T.Y.; Schlenz, A.R.; Lam, A.T.; Liao, J.C. Building Carbon-Carbon Bonds Using a Biocatalytic Methanol Condensation Cycle. Proc. Natl. Acad. Sci. USA 2014, 111, 15928-15933. [CrossRef]

145. Bogorad, I.W.; Lin, T.S.; Liao, J.C. Synthetic Non-Oxidative Glycolysis Enables Complete Carbon Conservation. Nature 2013, 502, 693-697. [CrossRef]

146. Henard, C.A.; Freed, E.F.; Guarnieri, M.T. Phosphoketolase Pathway Engineering for Carbon-Efficient Biocatalysis. Curr. Opin. Biotechnol. 2015, 36, 183-188. [CrossRef]

147. Henard, C.A.; Smith, H.K.; Guarnieri, M.T. Phosphoketolase Overexpression Increases Biomass and Lipid Yield from Methane in an Obligate Methanotrophic Biocatalyst. Metab. Eng. 2017, 41, 152-158. [CrossRef]

148. He, H.; Noor, E.; Ramos-Parra, P.A.; García-valencia, L.E.; Patterson, J.A.; de la Garza, R.I.D.; Hanson, A.D.; Bar-Even, A. In Vivo Rate of Formaldehyde Condensation with Tetrahydrofolate. Metabolites 2020, 10, 65. [CrossRef] [PubMed]

149. Harder, W.; Quayle, J.R. Aspects of Glycine and Serine Biosynthesis during Growth of Pseudomonas AM1 on C Compounds. Biochem. J. 1971, 121, 763-769. [CrossRef] [PubMed]

150. Vuilleumier, S.; Chistoserdova, L.; Lee, M.-C.; Bringel, F.; Lajus, A.; Zhou, Y.; Gourion, B.; Barbe, V.; Chang, J.; Cruveiller, S.; et al. Methylobacterium Genome Sequences: A Reference Blueprint to Investigate Microbial Metabolism of C1 Compounds from Natural and Industrial Sources. PLoS ONE 2009, 4, e5584. [CrossRef]

151. Yu, H.; Liao, J.C. A Modified Serine Cycle in Escherichia coli Coverts Methanol and $\mathrm{CO}_{2}$ to Two-Carbon Compounds. Nat. Commun 2018, 9, 1-10. [CrossRef]

152. Yishai, O.; Goldbach, L.; Tenenboim, H.; Lindner, S.N.; Bar-Even, A. Engineered Assimilation of Exogenous and Endogenous Formate in Escherichia coli. ACS Synth. Biol. 2017, 6, 1722-1731. [CrossRef]

153. Vieira, G.; Carnicer, M.; Portais, J. FindPath: A Matlab Solution for in Silico Design of Synthetic Metabolic Pathways. Bioinformatics 2014, 30, 2986-2988. [CrossRef]

154. Cotton, C.A.R.; Claassens, N.J.; Benito-Vaquerizo, S.; Bar-Even, A. Renewable Methanol and Formate as Microbial Feedstocks. Curr. Opin. Biotechnol. 2020, 62, 168-180. [CrossRef]

155. Bar-Even, A. Formate Assimilation: The Metabolic Architecture of Natural and Synthetic Pathways. Biochemistry 2016, 55, 3851-3863. [CrossRef] [PubMed]

156. Kim, S.; Lindner, S.N.; Aslan, S.; Yishai, O.; Wenk, S.; Schann, K.; Bar-Even, A. Growth of E. coli on Formate and Methanol via the Reductive Glycine Pathway. Nat. Chem. Biol. 2020, 16, 538-545. [CrossRef]

157. Siegel, J.B.; Smith, A.L.; Poust, S.; Wargacki, A.J.; Bar-Even, A.; Louw, C.; Shen, B.W.; Eiben, C.B.; Tran, H.M.; Noor, E.; et al Computational Protein Design Enables a Novel One-Carbon Assimilation Pathway. Proc. Natl. Acad. Sci. USA 2015, 112, 3704-3709. [CrossRef] [PubMed]

158. Mao, Y.; Yuan, Q.; Yang, X.; Liu, P.; Cheng, Y.; Luo, J.; Liu, H.; Yao, Y.; Sun, H.; Cai, T.; et al. Non-Natural Aldol Reactions Enable the Design and Construction of Novel One-Carbon Assimilation Pathways in Vitro. Front. Microbiol. 2021, 12, 1-13. [CrossRef]

159. Lu, X.; Liu, Y.; Yang, Y.; Wang, S.; Wang, Q.; Wang, X.; Yan, Z.; Cheng, J.; Liu, C.; Yang, X.; et al. Constructing a Synthetic Pathway for Acetyl-Coenzyme A from One-Carbon through Enzyme Design. Nat. Commun. 2019, 10, 1-10. [CrossRef]

160. Yang, X.; Yuan, Q.; Luo, H.; Li, F.; Mao, Y.; Zhao, X. Systematic Design and in Vitro Validation of Novel One-Carbon Assimilation Pathways. Metab. Eng. 2019, 56, 142-153. [CrossRef]

161. Jiang, H.; Lu, X.; Liu, Y.; Yang, Y.; Lu, L.; Yang, S.; Gou, J. Enzyme for Synthesizing Hydroxyl Acetaldehyde and/or 1, 3Dihydroxyacetone by Catalyzing Formaldehyde and Applications Thereof. U.S. Patent Application 16/483,716; WO/2018/153306 A1, 2017.

162. Schneider, S.; Gutiørrez, M.; Sandalova, T.; Schneider, G.; Clapøs, P.; Sprenger, G.A.; Samland, A.K. Redesigning the Active Site of Transaldolase TalB from Escherichia coli: New Variants with Improved Affinity towards Nonphosphorylated Substrates. Chem. Bio. Chem. 2010, 11, 681-690. [CrossRef]

163. Harms, N.; Reijnders, W.N.M.; Koning, S.; Van Spanning, R.J.M. Two-Component System That Regulates Methanol and Formaldehyde Oxidation in Paracoccus denitrificans. J. Bacteriol. 2001, 183, 664-670. [CrossRef]

164. Van Spanning, R.J.M.; De Vries, S.; Harms, N. Coping with Formaldehyde during C1 Metabolism of Paracoccus denitrificans. J. Mol. Catal. -B Enzym. 2000, 8, 37-50. [CrossRef]

165. Nokhal, T.-H.; Schlegel, H.G. Taxonomic Study of Paracoccus denitrificans. Int. J. Syst. Bacteriol. 1983, 33, 26-37. [CrossRef]

166. Ganesh, I.; Vidhya, S.; Eom, G.T.; Hong, S.H. Construction of Methanol-Sensing Escherichia coli by the Introduction of a Paracoccus denitrificans MxaY-Based Chimeric Two-Component System. J. Microbiol. Biotechnol. 2017, 27, 1106-1111. [CrossRef]

167. Selvamani, V.; Maruthamuthu, M.K.; Arulsamy, K.; Eom, G.T.; Hong, S.H. Construction of Methanol Sensing Escherichia coli by the Introduction of Novel Chimeric MxcQZ/OmpR Two-Component System from Methylobacterium organophilum XX. Korean J. Chem. Eng. 2017, 34, 1734-1739. [CrossRef]

168. Selvamani, V.; Ganesh, I.; Chae, S.; Maruthamuthu, M.K.; Hong, S.H. Engineering of Recombinant Escherichia coli towards Methanol Sensing Using Methylobacterium extroquens Two-Component Systems. Microbiol. Biotechnol. Lett. 2020, 48, 24-31. [CrossRef]

169. Bazurto, J.V.; Nayak, D.D.; Ticak, T.; Davlieva, M.; Lee, J.A.; Hellenbrand, C.N.; Lambert, L.B.; Benski, O.J.; Quates, C.J.; Johnson, J.L.; et al. EfgA Is a Conserved Formaldehyde Sensor That Leads to Bacterial Growth Arrest in Response to Elevated Formaldehyde. PLOS Biol. 2021, 19, 1-42. [CrossRef] [PubMed] 
170. Bazurto, J.V.; Riazi, S.; Alton, S.D.; Deatherage, D.E.; Bruger, E.L.; Barrick, J.E.; Marx, C.J. Global Transcriptional Response of Methylorubrum extorquens to Formaldehyde Stress Expands the Role of EfgA and Is Distinct from Antibiotic Translational Inhibition. Microorganisms 2021, 9, 347. [CrossRef] [PubMed]

171. Bazurto, J.V.; Bruger, E.L.; Lee, J.A.; Lambert, L.B. Formaldehyde-Responsive Proteins TtmR and EfgA Reveal a Trade-off between Formaldehyde Resistance and Efficient Transition to Methylotrophy in Methylorubrum extorquens. J. Bacteriol. 2021, 203, e00589-20. [CrossRef]

172. Bozdag, A.; Komives, C.; Flickinger, M.C. Growth of Bacillus methanolicus in $2 \mathrm{M}$ Methanol at $50{ }^{\circ} \mathrm{C}$ : The Effect of High Methanol Concentration on Gene Regulation of Enzymes Involved in Formaldehyde Detoxification by the Ribulose Monophosphate Pathway. J. Ind. Microbiol. Biotechnol. 2015, 42, 1027-1038. [CrossRef]

173. Zhu, R.; Zhang, G.; Jing, M.; Han, Y.; Li, J.; Zhao, J.; Li, Y.; Chen, P.R. Genetically Encoded Formaldehyde Sensors Inspired by a Protein Intra-Helical Crosslinking Reaction. Nat. Commun. 2021, 12, 1-13. [CrossRef]

174. Brown, N.L.; Stoyanov, J.V.; Kidd, S.P.; Hobman, J.L. The MerR Family of Transcriptional Regulators. FEMS Microbiol. Rev. 2003, 27, 145-163. [CrossRef]

175. Kidd, S.P.; Potter, A.J.; Apicella, M.A.; Jennings, M.P.; McEwan, A.G. NmIR of Neisseria gonorrhoeae: A Novel Redox Responsive Transcription Factor from the MerR Family. Mol. Microbiol. 2005, 57, 1676-1689. [CrossRef]

176. Stroeher, U.H.; Kidd, S.P.; Stafford, S.L.; Jennings, M.P.; Paton, J.C.; McEwan, A.G. A Pneumococcal MerR-like Regulator and S-Nitrosoglutathione Reductase Are Required for Systemic Virulence. J. Infect. Dis. 2007, 196, 1820-1826. [CrossRef]

177. Auchter, M.; Arndt, A.; Eikmanns, B.J. Dual Transcriptional Control of the Acetaldehyde Dehydrogenase Gene ald of Corynebacterium glutamicum by RamA and RamB. J. Biotechnol. 2009, 140, 84-91. [CrossRef]

178. Giedroc, D.P.; Arunkumar, A.I. Metal Sensor Proteins: Nature's Metalloregulated Allosteric Switches. Dalt. Trans. 2007, No. 29, 3107-3120. [CrossRef]

179. Higgins, K.A.; Giedroc, D. Insights into Protein Allostery in the Csor/Rcnr Family of Transcriptional Repressors. Chem. Lett. 2014, 43, 20-25. [CrossRef] [PubMed]

180. Denby, K.J.; Iwig, J.; Bisson, C.; Westwood, J.; Rolfe, M.D.; Sedelnikova, S.E.; Higgins, K.; Maroney, M.J.; Baker, P.J.; Chivers, P.T.; et al. The Mechanism of a Formaldehyde-Sensing Transcriptional Regulator. Sci. Rep. 2016, 6, 1-15. [CrossRef] [PubMed]

181. Osman, D.; Piergentili, C.; Chen, J.; Sayer, L.N.; Usón, I.; Huggins, T.G.; Robinson, N.J.; Pohl, E. The Effectors and Sensory Sites of Formaldehyde-Responsive Regulator FrmR and Metal-Sensing Variant. J. Biol. Chem. 2016, 291, 19502-19516. [CrossRef] [PubMed]

182. Rohlhill, J.; Sandoval, N.R.; Papoutsakis, E.T. Sort-Seq Approach to Rngineering a Formaldehyde-Inducible Promoter for Dynamically Regulated Escherichia coli Growth on Methanol. ACS Synth. Biol. 2017, 6, 1584-1595. [CrossRef] 